Federal Reserve Bank of Minneapolis

Research Department

\title{
Shrinking Money and Monetary Business Cycles
}

\author{
Harold L. Cole and Lee E. Ohanian*
}

Working Paper 579

March 1997

\begin{abstract}
In the postwar period velocity has risen so sharply in the U.S. that the ratio of money to nominal output has fallen by a factor of three. We analyze the implications of shrinking money for the real effects of a monetary shock in two classes of equilibrium monetary business cycle models: limited participation (liquidity) models and predetermined (sticky) price models. We show that the liquidity model predicts that a rise in velocity leads to a substantial reduction in the real effects of a monetary shock. In sharp contrast, we show that the real effects of a monetary shock in the sticky price model are largely invariant to changes in velocity. We provide evidence that suggests that the real effects of monetary shocks have fallen over the postwar period.
\end{abstract}

*Cole, Federal Reserve Bank of Minneapolis; Ohanian, Federal Reserve Bank of Minneapolis and University of Minnesota. We thank V.V. Chari, Larry Christiano, Narayana Kocherlakota, Robert Lucas, Ed Prescott, Tom Sargent, Nancy Stokey. The views expressed herein are those of the authors and not necessarily those of the Federal Reserve Bank of Minneapolis or the Federal Reserve System. 


\section{Introduction}

A striking and widely documented feature of U.S. postwar data is that velocity has increased so much that the ratio of money to nominal output has fallen by a factor of three. ${ }^{1}$ This paper examines what the relative shrinking of the supply of money implies for monetary business cycle models. We analyze the implications of accounting for this monetary trend in two widely used classes of monetary business cycle models: limited participation (liquidity) models, and predetermined (sticky) price models. ${ }^{2}$ We find that accounting for this trend in velocity leads to a dramatic reduction in the real effects of a monetary shock in the liquidity model but leaves the real effects unchanged in the sticky price model. The different predictions of the two models suggest a natural way to evaluate them. We present evidence that suggests that the real effects of monetary shocks have fallen during the postwar period. This evidence is easy to interpret within the framework of the liquidity model, but is harder to reconcile with the sticky price model.

The difference in the implications of this monetary trend for these two models is due to fundamental differences in how monetary shocks have real effects. In the sticky price model, money is nonneutral due to frictions associated with pricing in commodity markets. In the liquidity model, money is nonneutral due to frictions in transacting in asset markets. We show that the factors that are commonly seen as contributing to the increase in velocity have the effect, implicitly or explicitly, of reducing the importance of the financial frictions that are central to the liquidity model.

Our findings imply that there is an important connection between velocity and the real effects of monetary shocks in the liquidity model. Consequently, given the trend in velocity, the liquidity model is a fundamentally nonstationary model. Since there is no direct connection between velocity and the effects of monetary shocks in the sticky price model, this

\footnotetext{
${ }^{1}$ See Nelson and Gould (1974), Goldfeld (1976), Friedman and Schwartz (1982), Judd and Scadding (1982), Bordo and Jonung (1987), Lucas (1988), and Stock and Watson (1993) to name just a few.

${ }^{2}$ The third main class of monetary business cycle models is the misperceptions model of Lucas (1972). Since the misperceptions model does not allow for an economywide capital market, it is difficult to incorporate it into this study. In Section 7, we heuristically study the implications of changes in velocity for the misperceptions model.
} 
trend in velocity can be ignored in this model for the purposes of business cycle analysis.

We consider three factors that are widely cited in the empirical monetary literature as contributing to the increase in velocity. The first factor is the trend increase in inflation and nominal interest rates that occurred over much of the postwar period, which motivates individuals to economize on real balances. This factor has been analyzed by a number of authors including Friedman and Schwartz (1982), and is also widely cited in the money demand literature (see for example, Lucas (1990), and Stock and Watson (1993)). The second factor is an increase in the frequency of asset market transactions that allows households and firms to hold fewer real balances. One popular explanation for more frequent transactions is the development of financial markets that has lowered the cost of transacting. The effects of financial development on this ratio have been studied by Friedman and Schwartz (1982), Bordo and Jonung (1987), among others. The third factor is a decline in the use of money as a medium of exchange and an increase in the use of alternative means of transactions, such as a greater availability of credit arrangements. Friedman and Schwartz (1982), Clower (1969), and Hicks (1967) have discussed reductions in money's role as a medium of exchange. To understand whether the implications of changes in this ratio for the real effects of monetary shocks are sensitive to the specific mechanisms that generate the increase in velocity, we investigate the effects of changes in velocity in these models that arise from each of these three widely cited factors.

To conduct our analysis, we construct fairly standard versions of a sticky price model and a liquidity model that are modified to allow for cash and credit goods. We analyze the effect of changes in the ratio of money to nominal output on the real effect of an unexpected monetary shock in both models by separately incorporating each one of the three factors into the model. Thus, our analysis consists of three separate experiments. We conduct the first experiment by analyzing both models under low nominal interest rates (low average rates of money growth) and high nominal interest rates (high average rates of money growth). For both the sticky price model and the liquidity model, we compute the equilibrium and evaluate the differences in the effect of a monetary shock on output across equilibria with different 
average rates of inflation and interest. The second experiment is conducted by increasing the frequency that households and firms transact in asset markets. The third experiment is conducted by reducing the number of goods that must be purchased with cash. As in the first experiment, we compute the equilibrium for each model for each experiment and evaluate the differences of the effect of a monetary shock. We show that in each of these experiments, the real effects of a monetary shock are substantially reduced in the liquidity model and largely unchanged in the sticky price model.

This paper is related to several different literatures. The paper draws on models developed in the monetary business cycle literature. Contributions to the literature on liquidity models include work by Grossman and Weiss (1984), Rotemberg (1984), Lucas (1990), Fuerst (1994), Christiano (1991), Christiano and Eichenbaum (1992), Schlaegenhauf and Wrase (1995), and King and Watson (1996). Contributions to the literature on sticky price models include Taylor (1979), Rotemberg (1984), Kiyotaki (1985), Mankiw (1985), Svensson (1986), Blanchard and Kiyotaki (1987), Ball and Romer (1989), King (1990), Cho and Cooley (1995), Ohanian, Stockman, and Kilian (1995), and Chari, Kehoe and McGrattan (1996). This paper, which studies the connection between velocity and business cycles, is naturally related to the literature that studies the connection between velocity and long-run growth (see, for example Ireland, (1994)) as well as the literature on money demand and financial innovation (see, for example, Prescott (1987), Cole and Stockman (1992) and Ireland (1995)). Our paper is also related to the work of Christiano, Eichenbaum, and Evans (CEE) (1996) who study sticky price models and liquidity models using vector autoregression methods (VAR). A surprising finding of CEE's analysis is that the impulse response functions implied by the two models are fairly similar along many dimensions. Our analysis differs from that of CEE in that it exploits long-run observations to understand important differences between these two models.

The paper is organized as follows. Section 2 presents the observations that form the basis of our analysis. Section 3 develops a simple sticky price model. Section 4 develops a simple liquidity model. In Section 5, we present simulations of the sticky price model and 
the liquidity model to evaluate the implications of changes in the ratio of money to nominal output on the real effects of money for the three different interpretations. Section 6 discusses the empirical implications of our analysis and presents some evidence that the real effects of monetary shocks have declined over time. Section 7 provides a heuristic discussion of the implications of the trend in the ratio of money to nominal output for the misperceptions model. Finally, section 8 presents a summary and conclusion.

\section{Velocity: 1950-1995}

The increase in the ratio of nominal output to money, or velocity, for different measures of money over the period from 1950-1995 is presented in Figures 1 and 2. Figure 1 shows that the ratio of nominal GDP to M1 (M1 velocity) has risen by a factor of about three between 1950 and 1980. Since then, the velocity of M1 has been roughly stationary ${ }^{3}$. However, it is important to note that the rise in M1 velocity may be understated, since it has been estimated that the use of U.S. currency outside the country has increased considerably. Recent estimates are that in 1995, more than half of the currency outstanding was held overseas and that during the 1990s, the overseas stock of currency grew at approximately three times the rate of the domestic stock (see Porter and Judson (1996)).

In most sticky price models and liquidity models used in business cycle studies, money is introduced using either a cash-in-advance (CIA) constraint or a shopping time technology. Thus, the central role of money in these models is that it facilitates trade by explicitly serving as a medium of exchange or by reducing transaction costs. Given this emphasis in the literature, it is natural to analyze M1, since it is the measure that most closely corresponds to a non-interest-bearing asset that is held primarily for its medium of exchange function ${ }^{4}$. An alternative to simple-sum monetary aggregates such as M1 are Divisia monetary aggre-

\footnotetext{
${ }^{3}$ The money supply data prior to 1959 was constructed by adding together unrevised currency and demand deposit data. Up until the mid-1970s, M1 was composed almost entirely of currency and demand deposits. The unrevised currency and demand deposit data differ from the revised figures that are available from 1959 on primarily in that their seasonal factors have not been adjusted.

${ }^{4}$ Bordo and Jonung (1987) note that the standard approach in applied work is to use M1 in models in which the key role of money is its medium of exchange function, while economists who study models that stress the asset function of money typically have chosen M2 for applied work (page 13).
} 
gates. (See for example Barnett, Offenbacher, and Spindt (1984)). This approach breaks the perfect substitutability assumption implicit in simple-sum aggregates, and instead weights components on the basis of the flow of monetary services. Divisia indexes for M1, M2, and M3 have been compiled recently by Thornton and Yue (1992). These data are presented in Figure 2, and show that there also have been significant increases in the ratios of nominal output to Divisia M1, M2, and M3. The rise in the velocity of Divisia M1 is roughly the same as for simple-sum M1 to nominal output (about a factor of 3), while the rise in the velocity of Divisia M2 and Divisia M3 is by factors of 2.5 and 2.1, respectively, over the 1963-1992 period. Note also that the velocity of Divisia M2 and M3 continue to rise after 1980.

\section{The Sticky Price Model}

The first monetary business cycle model we consider is the sticky price model in which prices are set in advance of the monetary (and other) shocks. To make the points that we want to establish as transparently as possible we consider a very simple version of this model.

We assume that there are a continuum of goods in each period indexed on the unit interval. Each good is produced by a monopolistic competitor who employs labor. All of the consumption goods are assumed to be nonstorable and have a linear production function given by $y_{t}(i)=z_{t} l_{t}(i)$, where $z_{t}$ denotes an aggregate real productivity shock and $l_{t}(i)$ denotes the amount of labor employed in the production of good $i$. Firms are owned by households, and the firm's profits $(\Pi)$ are distributed to the households. There is a representative consumer who supplies labor to the firms and who purchases the output of the firms. Time is discrete, and there are assumed to be an infinite number of periods indexed by $t=1,2, \ldots$.

We assume that the fraction $\gamma$ of the unit interval of goods, must be purchased with cash, while the remainder of the goods can be purchased with credit. We assume that the fraction $\alpha$ of both the cash and the credit goods have their prices set in the previous period, while the remainder of producers set their prices within the period after having observed the 
current state. Cash goods are indexed by $i \in[0, \gamma]$ and credit goods are indexed by $i \in(\gamma, 1]$. As in Lucas and Stokey (1987), cash goods sales result in currency receipts that accumulate during the period for sellers, while credit goods sales result in invoices that are settled at the beginning of the next period.

The state in period $t$ is given by $s_{t}=\left(z_{t}, M_{t-1}, g_{t}, p_{t}^{\text {cash }}, p_{t}^{\text {credit }}\right)$, where $M_{t-1}$ is the beginning-of-period money stock, $g_{t}$ is the gross growth rate of money, and the initial predetermined cash and credit prices are given by $p_{t}^{\text {cash }}:[0, \alpha \gamma] \rightarrow \Re_{+}$and $p_{t}^{\text {credit }}:(\gamma, \gamma+\alpha(1-$ $\gamma)] \rightarrow \Re_{+}$. The history $s^{t} \equiv\left\{s_{0}, s_{1}, \ldots, s_{t}\right\}$. We denote the set of period $t+1$ histories that is consistent with the current state $s^{t}$ as $s^{t+1}\left(s^{t}\right)$.

The timing within a period is as follows. First the asset market opens for trade. Here, agents have the sum of the cash balances from the previous period, the net value of receipts from credit good sales, and their cash transfers from the government, $T_{t}$. The cash transfer that an agent receives is given by $T_{t}=\left(g_{t}-1\right) M_{t-1}$. The agents choose how much of these funds to invest in currency or in bonds. We assume that there exist both state contingent and non-contingent bonds. After the asset market closes, the goods market opens. In the goods market, producers of flexible price goods choose a nominal price for their output. Given nominal prices, consumers decide how much to work and consume. Output of the fixed price good is demand-determined: consumers are assumed to be able to purchase as much of the output as they want at the predetermined price. This will be true as long as the predetermined price is greater than or equal to the marginal cost. Finally, the producers who must set their prices in advance choose the values of their prices for the next period.

We let $b_{t}$ denote the quantity of noncontingent bonds purchased and $R_{t+1}$ denote their gross return; while we let $q_{t}\left(s^{t+1}\right)$ denote the quantity of the state-contingent bonds purchased in period $t$, and we let $Q_{t}\left(s^{t+1}\right)$ denote the price in period $t$ of a state-contingent (discount) bond which pays one unit of output in period $t+1$. Given the representative agent construct, bonds are in zero net supply.

The consumer's preferences over a CES aggregator of current consumption, $c_{t}$, and labor 
effort, $l_{t}$, are given by

$$
\left\{\sum_{t=0}^{\infty} \sum_{s^{t}} \beta^{t} \pi\left(s^{t}\right) u\left(c_{t}\left(s^{t}\right), l_{t}\left(s^{t}\right)\right)\right\}
$$

where

$$
c_{t}=\left[\int c_{t}(i)^{\theta} d i\right]^{1 / \theta}, \text { and } l_{t}=\int l_{t}(i) d i
$$

and $\pi\left(s^{t}\right)$ denotes the probability of history $s^{t}$. The consumer's budget constraint in the asset market in period $t$ is given by

$$
\begin{aligned}
& \Pi_{t}\left(s^{t}\right)+R_{t}\left(s^{t-1}\right) b_{t-1}\left(s^{t-1}\right)+w_{t}\left(s^{t}\right) l_{t}\left(s^{t}\right)+\tilde{m}_{t-1}\left(s_{t-1}\right)+T_{t}\left(s^{t}\right)+q_{t-1}\left(s^{t}\right) \geq \\
& \int_{(\gamma, 1]} p_{t}\left(i ; s^{t}\right) c_{t}\left(i ; s^{t}\right) d i+m_{t}\left(s^{t}\right)+b_{t}\left(s^{t}\right)+\sum_{s^{t+1}\left(s^{t}\right)} Q_{t}\left(s^{t+1}\right) q_{t}\left(s^{t+1}\right),
\end{aligned}
$$

where $\Pi_{t}$ denotes the individuals' share of the firms' profits, $w_{t}$ denotes his wage rate, $\tilde{m}_{t-1}$ is the money left over from the goods market last period, and $m_{t}$ is the amount of currency he acquired in the asset market. ${ }^{5}$ We will assume that there is a non-binding lower bound on the consumer's net borrowing, which rules out Ponzi schemes. The consumer also faces a CIA constraint in the goods market which is given by

$$
\left.0 \leq \tilde{m}_{t+1}\left(s^{t}\right) \equiv m_{t}\left(s^{t}\right)-\int_{i \in[0, \gamma]} p_{t}\left(i ; s^{t}\right) c_{t}\left(i ; s^{t}\right)\right)
$$

\subsection{The consumer's problem}

The CES assumption allows us to derive a simple representation for the consumer's static demands for the different goods within the period as a function of his total desired spending, the relative price of the individual good, $p_{t}(i)$, and an appropriate price index $\bar{p}_{t}$. When we fix the amount that the consumer has decided to spend on the cash and credit goods, as well as the forgone interest associated with money holdings, his static problem of optimally allocating his spending for these goods is then given by

$$
\max _{m_{t}, c_{t}(i)}\left[\int c_{t}(i)^{\theta} d i\right]^{1 / \theta}
$$

\footnotetext{
${ }^{5}$ To keep the budget constraint as simple as possible, we omit the value of shares of enterprises held by the household. In equilibrium, there is no trade of these shares in this representative household economy.
} 
subject to

$$
\int p_{t}(i) c_{t}(i) d i=E_{t}-\left(R_{t+1}-1\right) m_{t}
$$

and (3.2), where $E_{t}$ is his desired spending level in period $t$. Next, if we define a new price system

$$
\tilde{p}_{t}(i)=\left\{\begin{array}{ll}
R_{t+1} p_{t}(i) & \text { for all } i \in[0, \gamma] \\
p_{t}(i) & \text { for all } i \in(\gamma, 1]
\end{array},\right.
$$

and assume that the CIA constraint always binds, then we can rewrite the consumer's optimization problem the following single budget constraint:

$$
\int \tilde{p}_{t}(i) c_{t}(i) d i=E_{t}
$$

This gives first order necessary conditions of the following form:

$$
c_{t}(i)^{\theta-1}=\tilde{p}_{t}(i) \lambda_{t} c_{t}^{(\theta-1) / \theta}
$$

where $\lambda_{t}$ is the Lagrangian on (3.4). Then, since

$$
E_{t}=\int \tilde{p}_{t}(i) c_{t}(i) d i=\int \tilde{p}_{t}(i)\left[\tilde{p}_{t}(i) \lambda_{t} c_{t}^{(\theta-1) / \theta}\right]^{\frac{1}{\theta-1}} d i
$$

this implies that

$$
\left[\lambda_{t} c_{t}^{(\theta-1) / \theta}\right]^{\frac{1}{\theta-1}}=\frac{E_{t}}{\int\left[\tilde{p}_{t}(i)\right]^{\frac{\theta}{\theta-1}} d i} .
$$

Hence, since an appropriate price index is such that

$$
\bar{p}_{t} c_{t}=E_{t},
$$

this implies that

$$
\bar{p}_{t}=\left[\frac{\left(\int \tilde{p}_{t}(i)^{\frac{\theta}{\theta-1}} d i\right)^{\frac{1}{\theta}}}{\int \tilde{p}_{t}(i)^{\frac{\theta}{\theta-1}} d i}\right]^{-1}=\left(\int \tilde{p}_{t}(i)^{\frac{\theta}{\theta-1}} d i\right)^{\frac{\theta-1}{\theta}} .
$$

Thus, we can express the consumer's choice of $c_{t}(i)$, given $c_{t}$ and $\bar{p}_{t}$, as

$$
c_{t}(i)=\tilde{p}_{t}(i)^{\frac{1}{\theta-1}} \frac{\bar{p}_{t} c_{t}}{\int\left[\tilde{p}_{t}(i)\right]^{\frac{\theta}{\theta-1}} d i}=\left(\frac{\tilde{p}_{t}(i)}{\bar{p}_{t}}\right)^{\frac{1}{\theta-1}} c_{t} .
$$


Next, making use of this price index, we can express the consumer's intertemporal problem with respect to $c_{t}$ and $l_{t}$ as

$$
\max \left\{\sum_{t=0}^{\infty} \sum_{s^{t}} \beta^{t} \pi\left(s^{t}\right) u\left(c_{t}\left(s^{t}\right), l_{t}\left(s^{t}\right)\right)\right\}
$$

subject to

$$
\begin{aligned}
& \Pi_{t}\left(s^{t}\right)+R_{t}\left(s^{t-1}\right) b_{t-1}\left(s^{t-1}\right)+w_{t}\left(s^{t}\right) l_{t}\left(s^{t}\right)+T_{t}\left(s^{t}\right)+q_{t-1}\left(s^{t}\right) \geq \\
& \bar{p}_{t}\left(s^{t}\right) c_{t}\left(s^{t}\right)+b_{t}\left(s^{t}\right)+\sum_{s^{t+1}\left(s^{t}\right)} Q_{t}\left(s^{t+1}\right) q_{t}\left(s^{t+1}\right) .
\end{aligned}
$$

This yields the following first-order conditions:

$$
\begin{gathered}
\beta^{t} \pi\left(s^{t}\right)\left\{u_{c}\left(c_{t}\left(s^{t}\right), l_{t}\left(s^{t}\right)\right)-\bar{p}_{t}\left(s^{t}\right) \lambda_{t}\left(s^{t}\right)\right\}=0, \\
\beta^{t} \pi\left(s^{t}\right)\left\{u_{l}\left(c_{t}\left(s^{t}\right), l_{t}\left(s^{t}\right)\right)+w_{t}\left(s^{t}\right) \lambda_{t}\left(s^{t}\right)\right\}=0, \\
-\beta^{t} \pi\left(s^{t}\right) \lambda_{t}\left(s^{t}\right)+R_{t+1}\left(s^{t}\right) \beta^{t+1} \pi\left(s^{t}\right) \sum_{s^{t+1}\left(s^{t}\right)} \pi\left(s^{t+1} \mid s^{t}\right) \lambda_{t+1}\left(s^{t+1}\right)=0, \\
-\beta^{t} \pi\left(s^{t}\right) \lambda_{t}\left(s^{t}\right) Q_{t}\left(s^{t+1}\right)+\beta^{t+1} \pi\left(s^{t}\right) \pi\left(s^{t+1} \mid s^{t}\right) \lambda_{t+1}\left(s^{t+1}\right)=0,
\end{gathered}
$$

where $\pi\left(s^{t+1} \mid s^{t}\right)$ denotes the probability of $s^{t+1}$ conditional on $s^{t}$. These conditions imply that in equilibrium, the following pricing conditions must be satisfied:

$$
\begin{gathered}
w_{t}\left(s^{t}\right)=-\frac{u_{l}\left(c_{t}\left(s^{t}\right), l_{t}\left(s^{t}\right)\right)}{u_{c}\left(c_{t}\left(s^{t}\right), l_{t}\left(s^{t}\right)\right) / \bar{p}_{t}\left(s^{t}\right)}, \\
R_{t+1}\left(s^{t}\right)=\frac{u_{c}\left(c_{t}\left(s^{t}\right), l_{t}\left(s^{t}\right)\right) / \bar{p}_{t}\left(s^{t}\right)}{\beta \sum_{s^{t+1}\left(s^{t}\right)}\left\{\pi\left(s^{t+1} \mid s^{t}\right) \frac{u_{c}\left(c_{t+1}\left(s^{t+1}\right), l_{t+1}\left(s^{t+1}\right)\right)}{\bar{p}_{t+1}\left(s^{t+1}\right)}\right\}}, \\
Q_{t}\left(s^{t+1}\right)=\frac{\beta \pi\left(s^{t+1} \mid s^{t}\right) u_{c}\left(c_{t+1}\left(s^{t+1}\right), l_{t+1}\left(s^{t+1}\right)\right) / \bar{p}_{t+1}\left(s^{t+1}\right)}{u_{c}\left(c_{t}\left(s^{t}\right), l_{t}\left(s^{t}\right)\right) / \bar{p}_{t}\left(s^{t}\right)}
\end{gathered}
$$

\subsection{The Producer's Problem With Flexible Prices}

The static problem of an individual producer of the cash good is

$$
\max _{p_{t}(i)}\left(p_{t}(i)-\frac{w_{t}\left(s^{t}\right)}{z_{t}\left(s^{t}\right)}\right) c_{t}\left(i ; p_{t}(i), \bar{p}_{t}, c_{t}\right)\left(\sum Q_{t+1}\left(s^{t+1}\right)\right)
$$


where $c_{t}\left(i ; p_{t}(i), \bar{p}_{t}, c_{t}\right)$ denotes the consumer demand function. Using (3.6), we can be rewrite the consumer's demand function as

$$
\max _{p_{t}(i)}\left(p_{t}(i)-\frac{w_{t}\left(s^{t}\right)}{z_{t}\left(s^{t}\right)}\right)\left(\frac{R_{t+1}\left(s^{t}\right) p_{t}(i)}{\bar{p}_{t}\left(s^{t}\right)}\right)^{\frac{1}{\theta-1}} c_{t}\left(s^{t}\right)\left(\sum Q_{t+1}\left(s^{t+1}\right)\right) .
$$

The associated first-order condition is

$$
\left(\frac{\theta}{\theta-1} p_{t}(i)^{\frac{1}{\theta-1}}-\frac{1}{\theta-1} \frac{w_{t}\left(s^{t}\right)}{z_{t}\left(s^{t}\right)} p_{t}(i)^{\frac{2-\theta}{\theta-1}}\right)\left(\frac{R_{t+1}\left(s^{t}\right)}{\bar{p}_{t}\left(s^{t}\right)}\right)^{\frac{1}{\theta-1}} c_{t}\left(s^{t}\right)\left(\sum Q_{t+1}\left(s^{t+1}\right)\right)=0,
$$

which implies that

$$
p_{t}(i)=\frac{w_{t}\left(s^{t}\right)}{z_{t}\left(s^{t}\right) \theta}
$$

This solution has the implication that the profit-maximizing price is a constant markup over marginal cost. The problem of a credit producer can be shown to yield an identical pricing equation.

\subsection{The Producer's Problem With predetermined Prices}

Defining $\tilde{Q}_{t}\left(s^{t+2}\right)$ to be the appropriate state-contingent two-period discount price, or

$$
\tilde{Q}_{t}\left(s^{t+2}\right)=Q_{t+1}\left(s^{t+1}\left(s^{t+2}\right)\right) Q_{t}\left(s^{t}\left(s^{t+2}\right)\right),
$$

the problem of an individual cash good producer who must set his price in advance is

$$
\max _{p_{t+1}(i)} E_{t}\left\{\left(p_{t+1}(i)-\frac{w_{t+1}\left(s^{t+1}\right)}{z_{t+1}\left(s^{t+1}\right)}\right)\left(\frac{R_{t+2}\left(s^{t+1}\right) p_{t+1}(i)}{\bar{p}_{t+1}\left(s^{t+1}\right)}\right)^{\frac{1}{\theta-1}} c_{t+1}\left(s^{t+1}\right) \tilde{Q}_{t}\left(s^{t+2}\right)\right\}
$$

The associated first-order condition is

$$
E_{t}\left\{\begin{array}{c}
{\left[\frac{\theta}{\theta-1} p_{t+1}(i)^{\frac{1}{\theta-1}}-\frac{1}{\theta-1} p_{t+1}(i)^{\frac{2-\theta}{\theta-1}} w_{t+1}\left(s^{t+1}\right) / z_{t+1}\left(s^{t+1}\right)\right] \times} \\
\left(\frac{R_{t+2}\left(s^{t+1}\right)}{\bar{p}_{t+1}\left(s^{t+1}\right)}\right)^{\frac{1}{\theta-1}} c_{t+1}\left(s^{t+1}\right) \tilde{Q}_{t}\left(s^{t+2}\right)
\end{array}\right\}=0
$$

Hence, the optimal predetermined price for the cash good

$$
p_{t+1}(i)=\frac{E_{t}\left\{\frac{w_{t+1}\left(s^{t+1}\right)}{\theta z_{t+1}\left(s^{t+1}\right)}\left(\frac{R_{t+2}\left(s^{t+1}\right)}{\bar{p}_{t+1}\left(s^{t+1}\right)}\right)^{\frac{1}{\theta-1}} c_{t+1}\left(s^{t+1}\right) \tilde{Q}_{t}\left(s^{t+2}\right)\right\}}{E_{t}\left\{\left(\frac{R_{t+2}\left(s^{t+1}\right)}{\bar{p}_{t+1}\left(s^{t+1}\right)}\right)^{\frac{1}{\theta-1}} c_{t+1}\left(s^{t+1}\right) \tilde{Q}_{t}\left(s^{t+2}\right)\right\}} .
$$

The optimal predetermined price for the credit good is quite similar 


$$
p_{t+1}(i)=\frac{E_{t}\left\{\frac{w_{t+1}\left(s^{t+1}\right)}{\theta z_{t+1}\left(s^{t+1}\right)}\left(\frac{1}{\bar{p}_{t+1}\left(s^{t+1}\right)}\right)^{\frac{1}{\theta-1}} c_{t+1}\left(s^{t+1}\right) \cdot \tilde{Q}_{t}\left(s^{t+2}\right)\right\}}{E_{t}\left\{\left(\frac{1}{\bar{p}_{t+1}\left(s^{t+1}\right)}\right)^{\frac{1}{\theta-1}} c_{t+1}\left(s^{t+1}\right) \cdot \tilde{Q}_{t}\left(s^{t+2}\right)\right\}} .
$$

An important implication of these conditions is that the predetermined prices differ only to the extent of the covariance (conditional on $s^{t}$ ) of $R_{t+2}\left(s^{t+1}\right)$ with $w_{t+1}\left(s^{t+1}\right), z_{t+1}\left(s^{t+1}\right)$, $c_{t+1}\left(s^{t+1}\right),\left\{Q_{t}\left(s^{t+2}\right) \mid s^{t+1}\right\}$, and $\bar{p}_{t+1}\left(s^{t+1}\right)$. Since the flexible cash and credit prices are the same, this suggests if the difference between the predetermined prices is also small, then the equilibrium outcomes in the sticky price model in terms of the response to a monetary shock will be largely invariant with respect to the size of the cash versus the credit sectors. Of course, it is likely to depend in an important way on the fraction of goods whose prices must be set in advance.

\section{The Liquidity Model}

Next, we consider a very simple version of the liquidity model. The liquidity model differs from the sticky price model in several respects. First, in the liquidity model there are no predetermined prices. Second, there is free entry and producers therefore behave as perfect competitors. Third, firms are assumed to face a CIA constraint in purchasing labor services, and are assumed to borrow these funds from financial intermediaries in the asset market. Fourth, consumers must decide the allocation of their beginning-of-period money holdings between what they will lend to the financial intermediaries and what they will take into the goods markets in order to acquire cash goods prior to the realization of the current monetary injection, or the productivity level. Finally, all monetary injections (or withdrawals) are conducted with a financial intermediary, which we shall call a bank.

The consumer's problem has two parts. First he must decide how he will divide his initial money holdings, which we will denote by $\omega$, between what he will take into the goods market, $m_{t}$, and what he will take into the asset market, $n_{t}$. Since in the asset market he will receive a transfer, $T_{t}$, his total money holdings in the asset market will be $n_{t}+T_{t}$. The consumer chooses $m_{t}$ and $n_{t}$ prior to the realization of $\left(g_{t}, z_{t}\right)$ (and, hence, $\left.T_{t}\right)$. In the asset market, 
the consumer deposits cash in a bank which offers the gross rate of return $R_{t}$. This return is determined after the realization of $\left(g_{t}, z_{t}\right)$. In the goods market, the consumer chooses how much of his cash to spend on cash goods and how much of the credit goods to acquire. The consumer also chooses how many hours to work given the wage rate offered by the firms.

We will simplify the exposition of the consumer's problem by implicitly imposing that the consumption levels of all cash goods will be the same, as will be the consumption levels of all credit goods. This constraint is without loss of generality given the concavity of preferences and the mobility of labor. The CES consumption aggregate is therefore given by

$$
c=\left[\gamma\left(c^{\text {cash }}\right)^{\theta}+(1-\gamma)\left(c^{\text {credit }}\right)^{\theta}\right]^{1 / \theta} \text {. }
$$

We also find it convenient to express the consumer's problem in a recursive fashion. The value function of the consumer given his initial money holdings, $V(\omega)$, is implicitly defined by

$$
V(\omega)=\max _{m, n} E_{g, z}\left\{\max _{c, l} u(c, l)+\beta E_{z^{\prime}} V\left(g^{\prime}, \omega^{\prime}, z^{\prime}\right)\right\},
$$

subject to the following three constraints. First, the initial constraint on the consumer's choice of $m$ and $n$,

$$
\omega=m+n
$$

Second, the constraint on the value of next period's wealth

$$
\omega^{\prime}=\pi+w l-\gamma p^{\text {cash }} c^{\text {cash }}-(1-\gamma) p^{\text {credit }} c^{\text {credit }}+m+R(g, z) \tilde{n}
$$

where since the monetary transfer is given directly to the intermediary, we define the deposited funds that are returned to the household in the next period as $\tilde{n}=n+T$. Third, the CIA constraint

$$
\gamma p^{c a s h} c^{c a s h} \leq m
$$

Looking first at the consumer's problem in the goods market, where he takes as given $n$ and $m$, implies the following set of first-order conditions:

$$
u_{c}\left[\gamma\left(c^{c a s h}\right)^{\theta}+(1-\gamma)\left(c^{c r e d i t}\right)^{\theta}\right]^{\frac{1-\theta}{\theta}}\left(c^{c a s h}\right)^{\theta-1}-p(\lambda+\mu)=0
$$




$$
\begin{gathered}
u_{c}\left[\gamma\left(c^{\text {cash }}\right)^{\theta}+(1-\gamma)\left(c^{\text {credit }}\right)^{\theta}\right]^{\frac{1-\theta}{\theta}}\left(c^{\text {credit }}\right)^{\theta-1}-p \lambda=0, \\
u_{l}+\lambda w=0
\end{gathered}
$$

where $\nu$ is the Lagrangian on (4.1), $\lambda$ is the Lagrangian on (4.2), and $\mu$ is the Lagrangian on (4.3). The envelope condition implies that

$$
\lambda=E \frac{d V\left(\omega^{\prime}\right)}{d \omega^{\prime}}=\nu^{\prime}
$$

The first-order conditions with respect to the consumer's beginning of period choice of $m$ and $n$ are

$$
\begin{gathered}
-\nu+E\{\lambda(g, z)+\mu(g, z)\}=0, \\
-\nu+E\{R(g, z) \lambda(g, z)\}=0 .
\end{gathered}
$$

Banks operate in a simple way in this model. They take cash from consumers and make cash loans to producers who face a CIA constraint in hiring labor. The banks' problem is given by

$$
\max R(g, z)(b-\tilde{n}) \text { subject to } b \leq \tilde{n} .
$$

If $R(g, z) \geq 0$, then the bank will accept as much cash as the consumer offers and loan it all to the firms.

Firms borrow money from the banks in the asset market, which they use to hire workers in order to produce output. Their problem is

$$
\max p z l-w l-(R(g, z)-1) b
$$

subject to

$$
w l \leq b
$$

Since firms are free to choose which goods they produce, and since the costs of production are the same across all goods, the price of the cash and the credit goods must be the same in equilibrium. We denote this price simply by $p \equiv p^{\text {cash }}=p^{\text {credit }}$. The firms' first-order condition with respect to $l$ is

$$
R(g, z) w=p z
$$


The market clearing conditions of the model are

$$
\begin{gathered}
l=\gamma l^{c a s h}+(1-\gamma) l^{c r e d i t}, \\
c^{c a s h}=z l^{c a s h}, \\
c^{c r e d i t}=z l^{c r e d i t}, \\
b=n+T .
\end{gathered}
$$

\section{Computational Experiments:}

In this section, we analyze the implications of changes in velocity for the real effects of an unexpected monetary shock in the sticky price and liquidity models. Each of the three experiments we conduct introduces separately one of the three main factors considered in the literature to be important for accounting for the increase: (1) reduced money holdings as a result of higher nominal interest rates, (2) reduced cost of asset market transactions, and (3) a reduction in money's role as a medium of exchange. We consider each one of these factors individually to keep our analysis as simple and transparent as possible. It is important to note that neither the literature nor we claim that any one of these factors is solely responsible for the substantial postwar increase in velocity over the entire post-war period.

To conduct the our three experiments we need to choose functional forms and parameter values. Since many of the parameters are specific to the experiment being undertaken, we discuss them in the relevant section. The following preference specification across all experiments is used commonly in the equilibrium business cycle literature:

$$
u(c, l)=\frac{\left[c^{\psi}(1-l)^{1-\psi}\right]^{1-\sigma}}{1-\sigma}-1
$$

This specification features unit substitution elasticity between the consumption aggregate and leisure, which insures that along a steady-state growth path labor input is constant. This specification also features constant intertemporal elasticity of substitution, which guarantees a constant real interest rate along the steady-state growth path. 
To facilitate our analysis of the effects of unexpected monetary shocks on output, we consider only monetary shocks and abstract from technology shocks. We specialize our experiments further by considering only i.i.d. monetary shocks. We restrict our attention to i.i.d. shocks so that we can abstract from the real variability that is caused by changes in anticipated inflation. In standard CIA models, expected inflation alters labor supply decisions, since wages earned in period $t$ cannot be spent until period $t+1$ and, thus, are taxed by inflation. By eliminating output fluctuations due to changes in anticipated inflation, our i.i.d. specification allows us to isolate the real effect of unexpected monetary shocks in each model. Persistent monetary shocks mixes the effect of anticipated inflation with the effect of a monetary shock, and are therefore more difficult to interpret. In all experiments, our measure of the real effect of an unexpected monetary shock is the percentage standard deviation of output that results from i.i.d. monetary shocks.

While the models generally do not admit an analytic solution, the equilibrium can be calculated by solving $N$ nonlinear equations in $N$ unknowns. Using a nonlinear equation solver, it is possible to achieve an arbitrarily high degree of accuracy in solving the model. We chose a termination criterion that the maximum deviation of any equation was no greater than e-04 percent. Thus, approximation error is not an issue with the computed equilibria of the models.

\subsection{Experiment 1: A Rise in Velocity Brought About by Higher Inflation}

In this experiment, we introduce into our models the first of the three factors that we consider, which is an increase in inflation and hence nominal interest rates. Between 1950 and 1980, interest rates rose substantially, reflecting a trend increase in the inflation rate from roughly 4 percent to about 13 percent. Standard money demand theory suggests that as the opportunity cost of holding money rises, the equilibrium quantity of real balances will fall. Many recent studies that analyze money demand stability (for example Lucas (1988), and Stock and Watson (1993)) suggest that this factor has been important. Therefore, in our first experiment, we analyze the effect of an unexpected monetary shock on output for 
both the sticky price and liquidity models in a low inflation-low interest rate (high velocity) environment and a high inflation-high interest rate (low velocity) environment.

While changes in interest rates may affect velocity through a variety of channels, the effect of high interest rates in this experiment raises velocity through the substitution of credit goods for cash goods. This is the standard channel through which changes in inflation affect this ratio in cash and credit good models (for example Lucas $(1988,1987)$ ).

For this set of simulations, we choose the following parameter values for the model. The length of a period is one quarter, and we set $\beta=0.993$. The parameter $\theta$ governs the substitutability between cash and credit goods and, thus, governs the extent to which changes in inflation and interest rates affect velocity. We therefore experiment with different values for this parameter. For the sticky price model, it is necessary to choose the fraction of goods that have predetermined prices, $\alpha$. We compute the model with $\alpha=0.75$ (75 percent of goods have predetermined prices). We have experimented with different values for this parameter, but the nature of our findings is very similar ${ }^{6}$. We conduct the analysis for two values of overall curvature in utility that have been used widely in the literature: $\sigma=1$, or log over both the CES consumption aggregate and labor, and $\sigma=2$. The results for $\sigma=2$ were nearly identical to those for $\sigma=1$, but to conserve space are not presented. To evaluate whether the results are sensitive to changes in the fraction of goods subject to the CIA constraint, we use two values of the parameter $\gamma: \gamma=0.8$ (80 percent of goods must be acquired with preaccumulated cash), which is roughly the value used by Cooley and Hansen (1992), and $\gamma=0.4$. The preference parameter $\psi$, which is not important for fluctuations off the steady state growth path, is set at 0.5 .

Money growth rate shocks are i.i.d. For the low average inflation case, we choose quarterly shocks of $g^{\text {high }}=1.015$ and $g^{\text {low }}=1.005$. For the high average inflation case, we choose

\footnotetext{
${ }^{6}$ We keep the fraction of goods with prices set in advance the same for both the low and high inflation cases. We do this to isolate the effects of changes in $\frac{M}{P Y}$ for the impact of an unexpected money shock. It is reasonable to expect that more prices would change frequently in a high inflation environment. Since the effect of more frequent price changes reduces the effect of a money shock, this would reduce output variability in the sticky price model. The focus of the paper is on changes in $\frac{M}{P Y}$, and since the impact of more frequent price changes is well known, we do not incorporate it into the formal analysis.
} 
quarterly shocks of $g^{\text {high }}=1.0375$ and $g^{\text {low }}=1.0275$. This yields an average annualized inflation rate of 4 percent for the low inflation case, and 13 percent for the high case, which corresponds roughly to peak inflation in the United States. To focus our analysis on the implications of average higher nominal interest rates on the effect of a monetary shock, note that the percent standard deviation of money growth is about the same in the low and high inflation cases. Thus, this experiment focuses on one important element of postwar monetary policy: higher average inflation over 1950-1980, and abstracts from changes in uncertainty about inflation rates and interest rates. Therefore, it is not meant to capture all the main features of postwar monetary policy, but rather sheds light on the behavior of these two models under different average money supply growth rates.

\subsubsection{Sticky Price Model Findings}

The results for the sticky price model are presented in the left panel of Table 1. This table presents the ratio of $\frac{P Y}{M}$ and the percent standard deviation of output $(\% \sigma(Y))$ for the 4 percent average inflation case and the 13 percent average inflation case. To facilitate comparison across the two cases, the ratio of these two variables for the low and high inflation cases are also presented. The analysis is conducted for three values of $\theta$ and two values of $\gamma$.

The main finding for the sticky price model is that the effect of an unexpected monetary shock on output is invariant to changes in the average growth rate of money and associated changes in $\frac{P Y}{M}$. For example, with $\theta=0.99$ and $\gamma=0.8$, an increase in the average inflation

rate from 4 percent to 13 percent induces a rise in $\frac{P Y}{M}$ by a factor of over 5 (9.52 to 52.63 ), but output variability is nearly unchanged. In this case, the percent standard deviation of output is 0.995 percent when inflation averages 4 percent and is 0.979 percent when inflation averages 13 percent. The increase in $\frac{P Y}{M}$ is even sharper with $\theta=0.99$ and $\gamma=0.4$, (an increase in the inflation rate from 4 percent to 13 percent increases velocity by a factor of 9), but output variability in the low and high inflation cases remains about the same: 0.993 percent in the low inflation case and 0.978 percent in the high inflation case. The findings are similar for lower values of $\theta$ (lower elasticity of substitution between cash and credit 
goods), in that output variability is again invariant to changes in $\frac{P Y}{M}$. The only difference is that with a lower elasticity of substitution between cash and credit goods, the rise in $\frac{P Y}{M}$ is less dramatic.

\subsubsection{Liquidity Model Findings}

We find that changes in the average growth rate of money have very different effects in the liquidity model. Our first main finding is that $\frac{P Y}{M}$ is less sensitive to changes in the inflation rate in the liquidity model than in the sticky price model. For example, with $\theta=0.99$ and $\gamma=0.8, \frac{P Y}{M}$ rises about 36 percent when the inflation rate increases from 4 percent to 13 percent. The ratio rises about 12 percent with $\theta=0.99$ and $\gamma=0.4$, and lower values of $\theta$ produce even smaller increases.

Our second main finding in the liquidity model is that the effect of an unexpected monetary shock on output is very sensitive to changes in $\frac{P Y}{M}$. Any change in the inflation rate that induces a rise in $\frac{P Y}{M}$ of about 10 percent or greater also reduces output variability considerably. With $\theta=0.99$ and $\gamma=0.8, \frac{P Y}{M}$ rises by 36 percent in response to an increase in the inflation rate from 4 percent to 13 percent, while the percent standard deviation of output falls by a factor of 6 ; declining from 0.432 percent in the low inflation case to 0.077 percent in the high inflation case. Even relatively small increases in $\frac{P Y}{M}$ are associated with significant declines in the real effect of a monetary shock: with $\theta=.95$, and $\gamma=.4, \frac{P Y}{M}$ rises only about 9 percent in response to an increase in the inflation rate from 4 percent to 13 percent. However, the percent standard deviation of output falls by 27 percent in this case. These results stand in sharp contrast to those for the sticky price model, in which the real effect of a monetary shock is virtually invariant to changes in $\frac{P Y}{M}$.

This sensitivity reflects the fact that the effect of a monetary shock in this model depends on how much money is in the asset market. If very little money is in the asset market, a 1 percent increase in the total money supply has a large effect, because it increases loanable funds substantially. In this experiment, high inflation rates lead households to substitute

out of cash goods into credit goods, and as a consequence, $\frac{P Y}{M}$ rises. Since spending on cash 
goods has fallen, the fraction of the money stock in the asset market increases, and the real effect of a monetary shock of a given size falls.

\subsection{Experiment 2: A Rise in Velocity Due to Increased Frequency of Asset Market Transactions}

In this experiment, we consider the second factor, which is that households and firms hold fewer real balances by transacting more frequently in asset markets. One popular reason for the increased frequency of transactions is declines in the cost of transacting due to the introduction of new technologies resulting from development of financial markets. For example, more frequent use of asset markets may reflect the use of automatic teller machines or improvements in corporate cash management (Beehler (1983) or Dotsey (1984)). Alternatively, more frequent use of asset markets could reflect an increase in the opportunity cost of holding money, such as rising interest rates.

We incorporate more frequent use of asset markets in a very simple way, by allowing households and firms to visit asset markets twice per period, rather than once as in the baseline model. This is accomplished by dividing each model period into two subperiods. The main change in the model is: First, that households consume and work in both subperiods. Second, that when households (and firms in the liquidity model) go once to the asset market within a period they face a single CIA constraint for both first and second subperiod consumption. Third, when households (and firms in the liquidity model) go twice to the asset market within a period they face two CIA constraints, one for each subperiod.

Between periods, households visit the bank. To isolate the effect of changes in $\frac{P Y}{M}$ that result from more frequent asset market transactions, the other dimensions of the model are kept the same as in the baseline model. In particular, the timing of information is identical: the date $t$ monetary shocks occur once per period, at the beginning of the period. While this extension does not model the specific changes that result in more frequent asset market transactions, it provides a simple way to capture the main feature, that households and firms hold fewer real money balances by transacting more frequently.

This division of the model period implies the following modification of the lifetime utility 
function:

$$
\max E_{0} \sum_{t=0}^{\infty} \beta^{t}\left[u\left(c_{1 t}, l_{1 t}\right)+u\left(c_{2 t}, l_{2 t}\right)\right],
$$

where $c_{1 t}$ is consumption for the first subperiod of date $t, c_{2 t}$ is consumption for the second subperiod of date $t$, and the utility function $u$ is common to both subperiods.

We consider how this extension works in the sticky price model. The sequence of events is as follows. At the beginning of date $t$, prices for both subperiods are set. Then, households visit the asset market for first subperiod transactions. The period $t$ monetary shock is realized, asset market transactions take place, and households exit the asset market with cash that will be used to acquire cash goods for the first subperiod. At the end of the first subperiod, households return to the asset market, transact, and exit the asset market with cash that is used to acquire cash goods for the second subperiod. Given this setup, consumption and labor input are the same for both subperiods.

This subperiod modification works in a similar way in the liquidity model. Monetary shocks occur once per period, at the beginning of the first subperiod. Before the realization of the monetary shock, the household divides their wealth between cash that will be used to acquire goods during the first subperiod, and funds that are deposited in the bank for the first subperiod. Those funds are loaned to firms. At the start of the second subperiod, the same sequence of events takes place: firms repay their loans, and households return to the asset market and divide wealth between cash used to acquire goods during the second subperiod and funds deposited in the bank. Deposited funds are then loaned to firms for the second subperiod.

We use the same parameters as in the first experiment, with the exception that we do not report results for different values of $\theta$. (Our results were not sensitive to variations in this parameter). Instead, we use $\theta=0.85$. The values for the two-state money growth shock are the same as in the low inflation case of the first experiment: $g^{\text {high }}=1.015$ and $g^{\text {low }}=1.005$. We use two values of overall utility curvature $(\sigma=1$ and $\sigma=2)$. The results from this experiment are presented in Table 2. This table presents $\frac{P Y}{M}$ and the percent 
standard deviation of output for the baseline model, in which households (and firms) visit the bank once, and the alternative model, in which they visit the bank twice.

The results for the sticky price model are presented in the left panel of Table 2. These results are very similar to those of the first experiment in that the effect of an unexpected monetary shock on output is invariant to changes in $\frac{P Y}{M}$. For example, by visiting the asset market twice during the period, households hold fewer cash balances; $\frac{P Y}{M}$ rises by a factor of 2 . However, the percent standard deviation of output in the baseline case of visiting the asset market once is identical to that in the alternative model of visiting the asset market twice. This invariance holds for both values of utility curvature $(\sigma=1$ and $\sigma=2)$. The invariance of the real effect of an unexpected monetary shock to changes in $\frac{P Y}{M}$ is due to the fact that in the sticky price model, the main source of nonneutrality is the expected money supply relative to the actual money supply over the interval in which prices are fixed; as long as this does not change, the real effect of a monetary shock does not change.

The results for the liquidity model are presented in the right panel of Table 2. These results are also very similar to those of the first experiment, in that the effect of an unexpected monetary shock on output is sensitive to changes in $\frac{P Y}{M}$. When households and firms visit the asset market twice per period, $\frac{P Y}{M}$ again rises by a factor of 2 . However, the percent standard deviation of output falls in half. This reflects the fact that in the baseline model, the monetary shock affects production over the entire period, since portfolios cannot be adjusted until the next period. In the alternative model, households can adjust their portfolios halfway through the period. Thus, the monetary shock affects production during the first subperiod, but not during the second.

\subsection{Experiment 3: A Rise in Velocity Due to a Reduction in Money's Role as a Medium of Exchange}

In this experiment, we consider the third factor, which is a decline in the use of money as a medium of exchange, reflecting an increased use of credit arrangements. We model this by varying the fraction of goods subject to the CIA constraint, which is given by the parameter $\gamma$. Also, as in the previous experiments, we set $\theta=0.85, \psi=0.5, \sigma=\{1,2\}$, and 
$g^{\text {high }}=1.015$ and $g^{\text {low }}=1.005$. As in the other two experiments, here we compute measures of $\frac{P Y}{M}$ and the percent standard deviation of output for each parameter configuration.

\subsubsection{Sticky Price Model Findings}

Using the sticky price model, we compute our results for two values of $\alpha, 0.75$ and 0.25 . We conduct the experiments for $\gamma$ that range from 1 (all goods must be purchased with preaccumulated cash) to 0 (virtually all goods are credit goods). ${ }^{7}$

In Table 3 we present the average values of $\frac{P Y}{M}$ for the two models. The results for the sticky price model are presented in the left panel. With all goods subject to the CIA constraint, the value of $\frac{P Y}{M}$ is 0.25 . This ratio rises to $\infty$ as the fraction of cash goods in the economy, $\gamma$, goes to 0 . In particular, in order to account completely for the threefold postwar increase in $\frac{P Y}{M}$, a decline in $\gamma$ from about 0.6 to 0.2 would be required. These values are insensitive to the value for the parameter $\alpha$.

The left panels of Table $4(\sigma=1)$ and $(\sigma=2)$ present the percent standard deviations of output for the sticky price model for different values of $\gamma$. These results show that changes in $\frac{P Y}{M}$ that are brought about by changes in the use of money as a medium of exchange (variations in the parameter $\gamma$ ) have little impact on the real effect of an unexpected monetary shock. For the case of log utility, we find that the percent standard deviation of output is identical for different values of $\gamma$.

In our simulations, we have found that if preferences are of the form

$$
\log (c)+v(1-l), \quad v \text { concave }
$$

the real effect of an unexpected monetary shock is invariant to changes in $\frac{P Y}{M}$. In the appendix, we provide an analytic result for this invariance for the case

$$
u(c, 1-l)=\log c-A l
$$

The intuition behind this result is simply that with these preferences and the i.i.d. assumption, the nominal interest rate is state-invariant. With equations (3.16) and (3.17), this

\footnotetext{
${ }^{7}$ With $\gamma=0$, only the good indexed by $i=0$ is a cash good.
} 
implies that the predetermined cash and credit prices are identical. Consequently, changing the fraction of cash versus. credit goods only alters the number of goods which are subject to the inflation tax. Since this tax is state-invariant, it reduces the level of output but not its volatility.

For $\sigma=2$, there is little effect of changes in $\gamma$ on the percent standard deviation of output. This invariance also holds for the two different values of $\alpha$; the main difference here is that higher values of $\alpha$ lead to larger real effects of monetary shocks in absolute terms.

\subsubsection{Liquidity Model Findings}

The right panel of table 3 presents the values of $\frac{P Y}{M}$ in the liquidity model. Here, as in the sticky price model, reducing $\gamma$ monotonically reduces this ratio. However, a rise of a factor of 2 is the maximum rise possible in this model. This is because with $\gamma=0$, all the money stock is in the asset market, and the nominal wage bill is equal to the nominal value of output. $^{8}$

The right panels of Table 4 present the percent standard deviations of output for different values of $\gamma$. The most striking feature of these statistics is the significant monotonic fall in the real effect of a monetary shock. This finding stand in stark contrast to our main finding from the sticky price model, in which the relative real effect of monetary shocks is essentially invariant to changes in the role of money as a medium of exchange. The fall in the real effect of a monetary shock reflects the fact that as more goods can be purchased with credit, the fraction of the money stock in the asset market increases.

In fact, as $\gamma \rightarrow 0$, all variability due to monetary shocks vanishes. In the liquidity model, monetary shocks have real effects because they alter the relative distribution of money balances between the asset market and the goods market. With $\gamma=0$, all the money is in the asset market, and monetary shocks cannot alter the relative dispersion of cash balances. In this case, the limited participation feature of the model disappears, and monetary shocks

\footnotetext{
${ }^{8}$ The omission of investment in this simple model is not important for the maximum twofold increase in $\frac{P Y}{M}$. For example, this rise would be roughly unchanged if capital were included in the production function with a reasonable share parameter, and investment were a credit good, as in Cooley and Hansen (1989), and investment were about 25 percent of output as in the data.
} 
cease to have real effects.

\subsection{Summary Discussion of the Three Experiments}

In sum, we find that in the liquidity model, a substantial rise in velocity leads to a considerable fall in the effect of an unexpected monetary shock on output for each experiment. However, in the sticky price model, real effects of unexpected monetary shocks are largely invariant to changes in velocity. These striking differences are due to the very different frictions that lead to monetary nonneutralities in these models. In the sticky price model, money is nonneutral largely because it is the numeraire; money has real effects because prices are set in advance and are denominated in currency. In the liquidity model, money is nonneutral because unexpected changes in the money supply must be intermediated through asset markets and cannot be allocated to households instantly. A rise in velocity reduces the real effect of a monetary shock for either of two mechanisms. First, if as in experiments 1 or 3 , it changes the equilibrium distribution of cash across markets by pushing cash out of the goods market and into the asset market. When a greater fraction of the money stock is in the asset market, an unexpected monetary shock of a given size has a smaller liquidity effect on interest rates, and results in a smaller change in real output and a larger effect on nominal prices. Second, if as in experiment 2, individuals are able to more quickly readjust their portfolios, this reduces the interval of time over which a portfolio misallocation, or liquidity effect, occurs. Consequently prices react more quickly to a monetary shock, while the impact on time aggregated output and interest rates is reduced.

\subsection{Preserving Stationarity in the Liquidity Model}

Given that all of the experiments that we conducte lead to a reduction in the real effects of monetary shocks in the liquidity model, a natural question is: Are there experiments that would raise velocity while preserving stationarity of the effects of monetary shocks in the liquidity model? The only experiment that we are aware of that would do this is the 
following. Suppose the CIA constraint on labor is

$$
\phi w l \leq b, 0<\phi \leq 1
$$

rather than

$$
w l \leq b,
$$

as in the standard model. The parameter $\phi$ determines the fraction of the firm's wage bill that must be satisfied with bank loans. In this version, stationarity of the effects of monetary shocks can be preserved only if $\phi$ and $\gamma$ fall by the same percentage.

We don't pursue this type of experiment for two reasons. First, the literature on corporate money demand suggests that firms are economizing on real balances because they are doing a better job of managing their portfolios (see Beehler (1983) or Dotsey (1984)). In particular, these authors point out that firms are now able to hold small inventories of cash as a consequence of an increased array of financial services offered by financial intermediaries. This observation motivates our second experiment. This observation from the firm money demand literature is not well-captured by the idea that labor has become less of a cash good. Second, the data does not support the knife-edge case of constant relative money balances between the household and business sectors. The flow of funds data for currency and deposits in the household and business sectors show that the relative values have change quite substantially over time. The ratio of household to business holdings of currency plus demand deposits has gone from a level of 1.7 in 1952 to a peak of 2.9 in 1980 to a level of 1.7 in 1995. Since the business sector includes sole proprietorships, the more relevant measure from the standpoint of the model may be with regard to the corporate sector. The variation in the ratio of household to corporate holdings of currency plus demand deposits is even more extreme, going from a level of 2.3 in 1952 to a peak of 5.0 in 1980 to a level of 2.5 in 1996. Accounting for these large swings in the relative levels of money holdings between the business and household sectors by variations in $\gamma$ and $\phi$ will generate a sharp upward swing in the effects of unanticipated monetary shocks between 1950 and 1980 and a sharp downward swing between 1980 and 1995. 
Our basic conclusion is that preserving stationarity in the liquidity model will be very difficult because of the connection between financial market frictions and the nonneutrality of money in this model.

\section{Empirical Implications}

Since the liquidity model predicts that the real effects of unexpected monetary shocks should be declining in U.S. data over the postwar period, while the sticky price model predicts that the real effects of unexpected monetary shocks should be constant over time, this suggests that analyzing the real effects of monetary shocks over time is a means of evaluating these two classes of models. Since money shocks cannot be observed directly, this analysis is a challenging enterprise. To provide some evidence on the real effects of monetary shocks over time, we construct a measure of the unexpected component of the growth rate of money. We then use our model to evaluate how the contemporaneous effect of unexpected money growth changes over time. Our findings suggest that the real effects are declining. Similar findings emerge from VAR studies, and we also summarize some of this evidence.

To provide some suggestive evidence on this issue we follow Barro (1977) and construct a measure of the monetary shock by regressing the growth rate of money on variables in the information set of the agents. We then estimate the contemporaneous effect of a monetary shock on output for three different subsamples of the 1950-1995 period. We construct the appropriate relationship that is implied by the liquidity model within which to measure the effect of a monetary shock on real output as follows. Since in the liquidity model the equilibrium relative price of the cash and credit goods is equal to one, the level of output is given by $y_{t}=z_{t} l_{t}$. Now, assume that the stochastic process that generates the log of the productivity level follows a random walk with drift, that is, $\log \left(z_{t}\right)=\log \left(z_{t-1}\right)+\mu+v_{t}$, where $v_{t}$ is the shock. The preferences in the model are deliberately chosen to be stationary with respect to trend growth in productivity; hence, the equilibrium process for labor can be represented as $l\left(g_{t}, v_{t}\right)$. If we take a log-linear approximation to the labor function, then

$$
\log \left(l_{t}\left(g_{t}, v_{t}\right)\right)=\eta_{0}+\eta_{1} g_{t}+\eta_{2} v_{t} .
$$


Hence, we can approximately represent the stochastic process for the growth rate of output implied by the model as

$$
\triangle \log \left(y_{t}\right)=\mu+\eta_{1} g_{t}+\varepsilon_{t},
$$

where $\varepsilon_{t}$ is a moving average error term. We estimate this form of the relationship between output and the money shock, since it is valid even if we allow for capital in the model.

We construct two different measures of the money shock variable. The first measure (shock 1) is the residuals from a regression the growth rate of M1 on four lags of itself, a constant, and a trend over each subperiod. The second measure of the shock (shock 2) is the residuals from a regression of the growth rate of $\mathrm{M} 1$ on a constant, a trend, and two lags each of the growth rates of real GDP, a commodity price index, the deflator, and two lags of the rate of return on T-bills over each subperiod. In Table 5, we report the results of regressing the growth rate of real GDP on a constant and each of our two measures of the money shock separately for each subperiod. The results are similar for both measures of unexpected money growth and are consistent with the implications of the liquidity model in that they show a substantial decline in the contemporaneous effect of a monetary shock. For both measures of the monetary shock, the coefficient on the shock is significantly different from zero in the first subperiod, falls roughly in half in the second subperiod, and drops roughly to zero in the third subperiod. ${ }^{9}$

\section{Table 5: Effects of Money Shocks on Output}

\begin{tabular}{|c||c|c|c|}
\hline Coefficient (robust S.E.) & $1950: 1-1965: 4$ & $1966: 1-1980: 4$ & $1980: 1-1995: 4$ \\
\hline \hline Shock 1 & $0.71(0.23)$ & $0.56(0.20)$ & $-0.04(0.07)$ \\
\hline Shock 2 & $0.93(0.25)$ & $0.38(0.26)$ & $0.04(0.11)$ \\
\hline
\end{tabular}

Many recent studies have analyzed the real effects of monetary shocks; the most widely used technique in this literature has been vector autoregression (VAR) methods. Some of these studies have formally analyzed the real effects of monetary shocks over time.

\footnotetext{
${ }^{9}$ The in results in Table 5 are not driven by a breakdown in the prediction equation for money growth. For example, the $\bar{R}^{2}$ 's for the more elaborate prediction equation (shock 2) were $0.41,0.31$, and 0.70 for the three subperiods respectively.
} 
Wong (1996) has conducted an evaluation of the effects of monetary shocks on output over time using the Christiano, Eichenbaum, and Evans (CEE) (1996) VAR model. The CEE VAR includes real output, aggregate prices, the federal funds rate, non-borrowed reserves, total reserves, and a commodity price index. Wong takes the CEE model and estimates the VARs using rolling samples. He considers both the CEE definition of a monetary shock (non-borrowed reserves) as well as the Bernanke-Blinder definition (federal funds rate). His main finding is that at most horizons, the effects of monetary shocks on output trend to zero over time. In addition, he finds that the liquidity effects of a monetary shock on interest rates also fall over time, and the effect of a monetary shock on the price level rises. Taken together, Wong's results suggest that the nonneutrality of monetary shocks is falling. These findings emerge for both of the definitions of a monetary shock that he considers. These findings are also not very sensitive to different identifying restrictions.

Pagan and Robertson (1995) also show that the effects of monetary shocks have become smaller in recent years. Their VAR model is similar to CEE in terms of the variables included. Using data from 1959, they find that effects of monetary shocks on output and on interest rates have fallen consistently over this period. They find very little evidence of a liquidity effect of money on interest rates since 1980. Moreover, the effect of a monetary shock on output seems to have declined consistently by a factor of two or three over the entire period. In addition, they note that the liquidity effect of monetary shocks on interest rates is disappearing over time, and that the price level becomes more responsive to monetary shocks over time.

Similar findings are also reported by Kuttner and Friedman (1992), who fit a variety of two-, three-, and four-variable VARs that include money, output, aggregate prices, interest rates, and/or other financial variables. They show that the fraction of output variation that is accounted for by unexpected monetary shocks declines over the postwar period, and they report that the Granger-causality of money to income also declines.

In summary, a generic finding that seems to emerge across different types of analyses that are conducted by different researchers is that the real effects of unexpected monetary 
shocks are declining over the postwar period. These findings are consistent with the liquidity model, which predicts that the effects of monetary shocks on output should decline as velocity increases. However, it is difficult to reconcile this evidence with the sticky price model, which predicts that the real effects of monetary shocks should be constant irrespective of changes in velocity.

\section{The Misperceptions Model}

Although sticky price and liquidity models have attracted relatively more attention in recent years, the misperceptions model has recently been revived by Cooley and Hansen (1996). Since the various misperceptions models of monetary business cycles, such as in Lucas (1972), Eden (1994), Lucas and Woodford (1994), Eden and Bental (1996) or Wallace (1996), do not explicitly allow for an alternative transaction technology, it is difficult to discuss formally the implications of changes in money's role as a medium of exchange on the real effects of unexpected monetary shocks in this model. For example, it is not clear how to introduce credit goods into this model, since this extension would also introduce an economywide interest rate, and it is well known that this renders money neutral. (See for example Barro 1980). Instead, we argue heuristically that if a means for reducing money's medium of exchange function were incorporated in these models, then they would likely imply that the magnitude of the real effect associated with a given percent increase in the money supply would decline as money's role as a medium of exchange declined.

In this class of models, unanticipated increases in money have real effects because of confusion between an increase in nominal and real demand. For the Lucas (1972) model, the equilibrium price function is given by

$$
p_{t}=\varphi\left(g_{t}\right) M_{t-1}
$$

where $M_{t}$ is the money stock in period $t, g_{t}$ is the gross growth rate of the money stock between $t-1$ and $t$, and the function $\varphi$ is continuous and a non-negative function. ${ }^{10}$ In the

\footnotetext{
${ }^{10}$ Note that our timing convention is slightly different from that of Lucas who denoted the money supply prevailing in period $t$ by $m_{t+1}$.
} 
Lucas model, there is a CIA constraint for all consumption goods. Suppose, instead, that only a fraction of the goods are required to be purchased with cash. We denote the output of cash goods as $y^{\text {cash }}$. When we use Lucas' original solution for the equilibrium price function, the modified CIA constraint is:

$$
y_{t}^{c a s h}=\frac{M_{t}}{p_{t}}=\frac{g_{t}}{\varphi\left(g_{t}\right)}
$$

Assuming that only the production of cash goods is affected by monetary shocks, we see that the change in total output as a result of the monetary shock is equal to the change in the output of cash goods. This is given by

$$
\% \Delta y_{t}=\frac{\Delta y_{t}^{c a s h}}{y_{t}}=\left[g_{t}-\bar{g} \varphi\left(g_{t}\right) \varphi(\bar{g})^{-1}\right] \frac{M_{t-1}}{p_{t} y_{t}},
$$

where $\bar{g}$ is the expected growth rate of the money supply and therefore $g_{t}-\bar{g}$ is the monetary shock.

There are two components in this expression that are important for determining the effect of an unexpected monetary shock on output: (1) the ratio of money to nominal

output $\left(\frac{M_{t-1}}{p_{t} y_{t}}\right)$, and (2) $\varphi$, the value of which is determined by the nature of the signal extraction problem faced by households. The decline in the ratio of money to nominal output, ceteris paribus, implies that the effect of a monetary shock on total output variability should decline proportionately. Moreover, since the variability of monetary shocks has been roughly constant over the postwar period, it seems reasonable to conjecture that the value of $\varphi$ has not changed much during this period. Thus, if the nature of the signal extraction problem has not changed, then the decline in the ratio of money to nominal output suggests that the real effect of an unexpected monetary shock in a modified version of the misperceptions model that includes both cash and credit goods should fall substantially.

\section{Conclusion}

In the postwar United States, money is shrinking relative to nominal output. In this paper, we study the implications of this trend for two popular classes of monetary business 
cycle models: liquidity models and the sticky price models. We construct versions of these models and simulate them to understand how increases in velocity over the postwar period would affect the real impact of a monetary shock. We consider separately three prominently mentioned factors behind the increase in velocity. The first factor is high inflation and is motivated by the money demand literature and the fact that over much of the postwar period, inflation increased considerably. The second factor is more frequent asset market transactions and is motivated in part by the financial development that has occurred in the postwar period. The third factor is a decline in the use of money as a medium of exchange and is motivated by the increased use of alternative transaction technologies, such as the greater use of credit cards.

Our analysis suggests that the real effect of an unexpected monetary shock in the sticky price model is invariant to factors that induce changes in velocity, while the real effect of an unexpected monetary shock in the liquidity model is extremely sensitive to the factors we consider. In particular, the liquidity model predicts that the real effect of a monetary shock should have fallen substantially in response to the observed threefold increase that has occurred over the postwar period. The differences between our findings for these two models are due to fundamental differences in the nonneutrality of money.

These results shed new light on these two models. In the sticky price model, money has real effects because it is the numeraire, and prices cannot be changed immediately in response to shocks. Our results show that if this numeraire role is not diminished and the nature and length of price stickiness is unchanged, then the real effects of a monetary shock are invariant to changes that affect transactions technologies, such as in the inflation rate or financial market frictions. This result for the sticky price model is interesting, since the focus of monetary theory is modeling money's medium of exchange role, rather than its unit of account role. We conclude that shrinking money does not have important implications for monetary business cycles in the sticky price model.

In the liquidity model, the nonneutrality of money is due to frictions that limit an individual's ability to transact in asset markets. Hence, anything that explicitly or implicitly 
reduces these frictions also reduces the real effect of an unexpected monetary shock. A striking long-run prediction therefore emerges from this model: if money continues to shrink, then monetary shocks will become unimportant as a source of cyclical fluctuations. The connection between velocity and the effects of monetary shocks in the liquidity model also raises questions about using a stationary version of this model to study postwar U.S. data. This finding contrasts sharply with the standard view in macroeconomics that low frequency components are unimportant for business cycle analysis and thus can be safely ignored.

Our theoretical findings indicate that we can evaluate these models by assessing changes in the real effects of monetary shocks over time. To provide some suggestive evidence along these lines, we constructed measures of monetary shocks, and used the liquidity model to assess the real effects of monetary shocks over time. We find that these effects have declined considerably over the postwar period, and note that similar findings have been reported by other researchers using different methods. The nonstationary liquidity model provides an interesting framework for understanding these empirical findings. While more work is required to evaluate the degree to which the effects of monetary shocks have changed over time, the theoretical findings presented in this paper provide a framework that can be used to sharply discriminate between these competing models.

\section{References}

[1] Ball, L. and D. Romer, "Are Prices too Sticky?", Quarterly Journal of Economics, 104: 507-24.

[2] Barnett, William A.; Offenbacher, Edward K.and Paul A. Spindt, "The New Divisia Monetary Aggregates", Journal of Political Economy, 92(6), December 1984, pages 1049-85.

[3] Barro, Robert, "Unanticipated Money Growth and Unemployment in the United States", American Economic Review, 67(2), (March 1977), pages 101-15. 
[4] Barro, R., "A Capital Market in an Equilibrium Business Cycle Model," Econometrica, 48 (September 1980), 1393-1417.

[5] Beehler, Paul Contemporary Cash Management: Principles, Practices, Perspectives. New York, Wiley 1983.

[6] Blanchard, O. J. and N. Kiyotaki, "Monopolistic Competition and the Effects of Aggregate Demand," American Economic Review, 77(4), 647-666.

[7] Chari, V.V., P. Kehoe, and E. McGrattan, "Sticky price Models of the Business Cycle: The persistence Problem," Research Department Staff Report 217, Federal Reserve Bank of Minneapolis, 1996.

[8] Christiano, L., "Modeling the Liquidity Effect of a Monetary Shock," Federal Reserve Bank of Minneapolis Quarterly Review, (Winter, 1991).

[9] Christiano, L. and M. Eichenbaum, "Liquidity Effects and the Monetary Transmission Mechanism," American Economic Review, 82(2), 346-353.

[10] Christiano, L., M. Eichenbaum and C. Evans, "The Effects of Monetary Policy Shocks: Some Evidence from the Flow of Funds," Review of Economics and Statistics, 78(1), (February, 1996), 16-34.

[11] Cho, J. and T. Cooley, "The Business Cycle with Nominal Contracts," Economic Theory, 6(1), June 1995, pages 13-33.

[12] Cole, Harold L. and Alan C. Stockman, "Specialization Transactions Technologies, and Money Growth," International Economic Review, 33(2), (May 1992), pages 283-298.

[13] Cooley, T. and G. Hansen, "The Inflation Tax in a Real Business Cycle Model," American Economic Review, 79(4), September 1989, pages 733-48.

[14] Dotsey, Michael, "An Investigation of Cash Management Practices and Their Effects on the Demand for Money," Federal Reserve Bank of Richmond Quarterly Review, 70, (September/October 1984), pages 3-12. 
[15] Eden, Benjamin, "The Adjustment of Prices to Monetary Shocks When Trade is Uncertain and Sequential", Journal of Political Economy, 102(3), (June, 1994), pages 493-509.

[16] Eden, Benjamin and Benjamin Bental, "Money and Inventories in an Economy with Uncertain and Sequential Trade, Journal of Monetary Economics. 37(3), (1996), pages 445-59

[17] Furest, T., "Liquidity, Loanable Funds, and Real Activity," Journal of Monetary Economics, 1992, 29(1), 3-24.

[18] Grossman, Sanford and Lawrence Weiss, "A Transactions-Based Model of the Monetary Transmission Mechanism", American Economic Review, 73(5), December 1983, pages $871-80$.

[19] Judd, John P. and John L. Scadding, "The Search for a Stable Money Demand Function: A Survey of the Post-1973 Literature", Journal of Economic Literature, 20(3), (September 1982), pages 993-1023.

[20] King, R. "Money and Business Cycles", forthcoming, Journal of Monetary Economics.

[21] King Robert G. and Mark W. Watson, "Money, Prices, Interest Rates and the Business Cycle", Review of Economics and Statistics, 78(1), February 1996, pages 35-53.

[22] Kuttner, Kenneth and Benjamin Friedman, "Money, Income, Prices, and Interest Rates", American Economic Review, Volume 82, Number 3, pages 472-492.

[23] Ireland, Peter N., "Money and Growth: An Alternative Approach", American Economic Review, 84(1), (March 1994), pages 47-65.

[24] Ireland, Peter N., "Endogenous Financial Innovation and the Demand for Money," Journal of Money Credit and Banking, 27(1), (February 1995), pages 107-123.

[25] Lucas, Robert E. Jr., "Expectations and the Neutrality of Money," Journal of Economic Theory, 31(1), April 1972, pages 103-24. 
[26] Lucas, Robert E. Jr., "Money Demand in the United States: A Quantitative Review", Carnegie Rochester Conference Series on Public Policy, 29(0), Autumn 1988, pages $137-67$.

[27] Lucas, Robert E. Jr., "Liquidity and Interest Rates," Journal of Economic Theory, 50(2), 1990, pages 237-264.

[28] Lucas, Robert E. Jr. and Nancy Stokey, Money and Interest in a Cash-in-Advance Economy," Econometrica, 55(3), May 1987, pages 491-513.

[29] Lucas, Robert E. Jr. and Michael Woodford, "Real Effects of Monetary Shocks in an Economy with Sequential Purchases," NBER Working Paper \#4250, January 1993.

[30] Mankiw, Gregory N., "Small Menu Costs and Large Business Cycles: A Macroeconomic Model", Quarterly Journal of Economics, 10(2), May 1985, pages 529-38.

[31] Ohanian, L., A. Stockman and L. Kilian, "The Effects of Real and Monetary Shocks in a Business Cycle Model with Some Sticky Prices," Journal of Money, Credit and Banking, 27(4) part 2, November 1996.

[32] Pagan, Adrian R., and John C. Robertson, "Resolving the Liquidity Effect", Federal Reserve Bank of St. Louis Review, May/June 1995, Volume 77, pages 33-54.

[33] Porter, Richard and Ruth Judson, "The Location of U.S. Currency: How Much is Abroad?", Federal Reserve Bulletin, 82(10), (October 1996), pages 883-903.

[34] Rotemberg, Julio J., "A Monetary Equilibrium Model with Transactions Costs", Journal of Political Economy, 92(1), February 1984, pages 40-58.

[35] Schlagenhauf, Don E. and Jeffery M. Wrase, "Liquidity and Real Activity in a Simple Open Economy Model", Journal of Monetary Economics, 35(3), (August 1995), pages 431-61. 
[36] Stock, James and Mark Watson, "A Simple Estimator of Cointegrating Vectors in Higher Order Integrated Systems", Econometrica, 61(4), (July 1993), pages 783-820.

[37] Svensson, Lars E. O., "Sticky Goods Prices, Flexible Asset Prices, Monopolistic Competition, and Monetary Policy", Review-of-Economic-Studies, 53(3), (July 1986), pages $385-405$.

[38] Taylor, John B., "Staggered Wage Setting in a Macro Model", American Economic Review, 69(2), (May 1979), pages 108-13.

[39] Thornton, Daniel L., and Piyu Yue, "An Extended Series of Divisia Monetary Aggregates", Federal Reserve Bank of Saint Louis Review, November $\backslash$ December 1992, pages $35-52$.

[40] Wong, Ka-Fu, "Variability in the Effects of Monetary Policy on Economic Activity", Memo, University of Wisconsin, 1996. 


\section{A. Simple Analytic Comparison of the Two Models}

In this section, we show analytically that changes in velocity have very different implications for the real effect of an unexpected monetary shock in the sticky price model and the liquidity model. For these analytic results, the increase in velocity is due to a decline in the use of money as a medium of exchange, which was the third factor in the increase in velocity we discussed. Recall that we model this reduction in the use of money as an increase in the fraction of goods that can be purchased with credit. For a special case of the sticky price model, we derive a pure invariance result, in that the real effect of an unexpected monetary shock does not depend on the parameter $\gamma$, which measures the fraction of goods subject to the CIA constraint. For a special case of the liquidity model, we derive a pure neutrality result, in that when all goods are credit goods $(\gamma=0)$, real variables are independent of the realization of the monetary shock. In both of these special cases we assume that the real shock, $z$, and the money growth shock $g$ are i.i.d. shocks..

The reason for this sharp dichotomy between the two models reflects the fundamental difference in how money has real effects in the two models. In the sticky price model, monetary shocks have real effects because they alter the intertemporal relative price of goods today and goods tomorrow. In this model, money has real effects primarily because of its numeraire function (unit of account). In the liquidity model, monetary shocks have real effects because they alter the relative distribution of money balances between the asset market and the goods market. With $\gamma=0$, all the money is in the asset market, and monetary shocks cannot alter the relative dispersion of cash balances. In this case, monetary shocks cease to have real effects.

\section{A.1. An Invariance Result for a Special Case of the Sticky Price Model}

Let us assume that the momentary utility over the consumption aggregate and labor take the following form:

$$
u(c, 1-l)=\log c-A l .
$$

Then, we can show that a number of key features of the economy, including the variability of output, are invariant to the extent to which goods must be acquired with cash or credit.

The assumption that the money supply and the technology parameter are i.i.d. enables us to restrict our attention to Markov equilibria which are functions of $s_{t}=\left(M_{-1}, p^{1}, p^{2}, g, z\right)$.

First, we conjecture that the equilibrium interest rate is invariant to the current state, which implies that the interest rate can be written as:

$$
R=\frac{1}{E\left\{\beta / g^{\prime}\right\}}
$$

Now, we note that since the future sticky prices are completely determined by forward looking considerations, and given our assumption that the shock process is i.i.d., there will be only one set of prices $\left(p^{1}, p^{2}\right)$ in equilibrium. The invariance of the interest rate implies from equations (3.16) and (3.17) that the credit and cash predetermined prices are equal. 
Next, conjecture that the price set in period $t$ multiplied by $\left(M_{t} / \gamma\right)$ will be time invariant, and denote this price by $p^{s}$.

If we make use of (3.3), (3.5), and (3.15), then we can derive the following equation for the price index:

$$
\bar{p}(s)=\left\{\left(\gamma R^{\frac{\theta}{\theta-1}}+(1-\gamma)\right)\left(\alpha\left(\frac{M p^{s}}{g \gamma}\right)^{\frac{\theta}{\theta-1}}+(1-\alpha)\left(\frac{w(s)}{z \theta}\right)^{\frac{\theta}{\theta-1}}\right)\right\}^{\frac{\theta-1}{\theta}},
$$

which, given our expression for the wage in (3.12), can be written as

$$
\bar{p}(s)=\left\{\left(\gamma R^{\frac{\theta}{\theta-1}}+(1-\gamma)\right)\left(\alpha\left(\frac{M p^{s}}{g \gamma}\right)^{\frac{\theta}{\theta-1}}+(1-\alpha)\left(\frac{A \bar{p}(s) c(s)}{z \theta}\right)^{\frac{\theta}{\theta-1}}\right)\right\}^{\frac{\theta-1}{\theta}} .
$$

If we make use of our expression for demand in equation (3.6), then the CIA constraint can similarly be written as

$$
M=\gamma\left[\alpha\left(\frac{M p^{s}}{g \gamma}\right)^{\frac{\theta}{\theta-1}}+(1-\alpha)\left(\frac{A \bar{p}(s) c(s)}{z \theta}\right)^{\frac{\theta}{\theta-1}}\right]\left(\frac{R}{\bar{p}(s)}\right)^{\frac{1}{\theta-1}} c(s),
$$

which makes use of the fact that $c / \bar{p}^{1 /(\theta-1)}=\bar{p} c \bar{p}^{-\theta /(\theta-1)}$. Equation (A.1) implies that expenditures on consumption are constant and are given by

$$
\bar{p}(s) c(s)=D \frac{M}{\gamma},
$$

where

$$
D \equiv \frac{\left(\gamma R^{\frac{\theta}{\theta-1}}+(1-\gamma)\right)}{R^{\frac{1}{\theta-1}}} .
$$

Equation (A.2) indicates that a simple neutrality result holds. The quantity of money per unit of the cash good is given by $M /\left(\gamma c^{\text {cash }}\right)$. Our neutrality result with respect to the effective money supply $M / \gamma$. We will thus normalize all prices by dividing by the effective money supply relative to the number of cash goods.

With this normalization, (A.2) implies that $\bar{p}(s) c(s)=D$. Substituting into (A.1) for $\bar{p}(s) c(s)$ gives us a simple expression for normalized $\bar{p}$ in terms of $\left(z, g, p^{s}\right)$ :

$$
\bar{p}=\left\{\left(\gamma R^{\frac{\theta}{\theta-1}}+(1-\gamma)\right)\left(\alpha\left(\frac{p^{s}}{g}\right)^{\frac{\theta}{\theta-1}}+(1-\alpha)\left(\frac{A D}{z \theta}\right)^{\frac{\theta}{\theta-1}}\right)\right\}^{\frac{\theta-1}{\theta}}
$$

and, consequently, a simple expression for $c=D / \bar{p}$. The key feature of (A.3) is that $\gamma$ (the fraction of goods that are subject to the CIA constraint) enters this equation through a state invariant multiplicative term, given that $R$ is independent of $\gamma$. Moreover, the implied expression for $c$ does not depend on the parameter $\gamma$. 
Some algebra on the resource constraint along similar lines to that used on the CIA constraint yields the following expression for labor:

$$
l\left(z, g, p^{s}\right)=\frac{1}{z}\left[\frac{\gamma R^{\frac{1}{\theta-1}}+(1-\gamma)}{R^{\frac{1}{\theta-1}}}\right] \frac{\left\{\left(\alpha\left(\frac{p^{s}}{g}\right)^{\frac{1}{\theta-1}}+(1-\alpha)\left(\frac{A D}{z \theta}\right)^{\frac{1}{\theta-1}}\right)\right\}}{\left\{\left(\alpha\left(\frac{p^{s}}{g}\right)^{\frac{\theta}{\theta-1}}+(1-\alpha)\left(\frac{A D}{z \theta}\right)^{\frac{\theta}{\theta-1}}\right)\right\}} .
$$

Note that here too $\gamma$ enters in through a state-invariant multiplicative term if $p^{s}$ is invariant with respect to $\gamma$.

We have thus far derived expressions for $(\bar{p}, c, l)$ in terms of $\left(z, g, p^{s}\right)$, given our assumptions with regard to $R$ and $p^{s}$, which we can use to solve for $p^{s}$. Given the constancy of the interest rate we can reduce the expressions for the sticky price in (3.16) and (3.17) to

$$
p^{s}=\frac{E\left\{\frac{A D g^{\prime}}{\theta z^{\prime}}\left(g^{\prime} \bar{p}^{\prime}\right)^{\frac{-1}{\theta-1}} c^{\prime} Q^{\prime \prime-1}\right\}}{E\left\{\left(g^{\prime} \bar{p}^{\prime}\right)^{\frac{-1}{\theta-1}} c^{\prime} Q^{\prime \prime-1}\right\}},
$$

where we have used a prime $\left(^{\prime}\right)$ to denote the value of the variable one period ahead and a double prime (") to denote the value of the variable two periods ahead. Making use of equation (3.14), we can derive the following expression:

$$
Q^{\prime \prime}=\left(\frac{\beta \bar{p}^{\prime} c^{\prime}}{g^{\prime \prime} \bar{p}^{\prime \prime} c^{\prime \prime}}\right)=\frac{\beta}{g^{\prime \prime}},
$$

where we have again made used (A.2). We can substitute (A.6) into (A.5) to get a single equation system to solve $p^{s}$ :

$$
p^{s}=\frac{A D}{\theta} \frac{E\left\{\frac{g^{\prime}}{z^{\prime}}\left(g^{\prime} \bar{p}^{\prime}\right)^{\frac{-1}{\theta-1}} c^{\prime}\right\}}{E\left\{\left(g^{\prime} \bar{p}^{\prime}\right)^{\frac{-1}{\theta-1}} c^{\prime}\right\}} .
$$

We can now verify that our solution will have the conjectured properties with respect to $R$ and $p^{s}$. First, note that if we use our expression for the interest rate in equation (3.13), then the constancy of $\bar{p}(s) c(s)$ verifies our conjecture with regard to the interest rate. Second, if we conjecture that future prices are constant, this implies that the future values of $\bar{p}$ and, hence, of $c$ are independent of the current state. Given equation (A.7), this implies that $p^{s}$ is a constant. Third, it is easy to see from the multiplicative way in which $\gamma$ enters all of our expressions for $(\bar{p}, c)$, and further since it appears symmetrically in the numerator and denominator of our expression in (A.7), that all terms involving this parameter will cancel in this expression and the solution to this nonlinear equation for $p^{s}$ will be invariant to $\gamma$.

Finally, note that the invariance of our normalized $p^{s}$ with respect to $\gamma$, along with our equation for labor, (A.4), implies that $\gamma$ affects $l$, and hence $y=z l$, by a state-invariant multiplicative factor. Therefore, it has no effect on the standard deviation of $l$ or $y$ relative to their respective means. Thus, this version of our sticky price model implies that the real effects of unexpected monetary shocks on output are completely invariant to changes in the use of money as a medium of exchange. 


\section{A.2. A Neutrality Result for a Special Case of the Liquidity Model}

Consider a version of the liquidity model in which there are no cash goods, only credit goods, and in which the physical state is assumed to follow a first-order Markov process. In this case, the model simplifies in a number of ways. First, there is no decision for the consumer with regard to his allocation of money; he will do at least as well by taking it all into the asset market as long as $R \geq 0$, hence we can take $n=1$. The consumer's optimal decisions with regard to $(l, c)$ (where $c=c^{\text {credit }}$ ), are characterized by (4.5), (4.6) and (4.8), along with his budget constraint. The bank's and the credit-good firm's problems are unchanged, so their behavior is still characterized by the same set of equations. It is easy to see that an equilibrium of this model is a set of functions $(l, R)(z, g)$ such that the following set of equations are satisfied for all $(z, g)$ :

$$
\frac{-u_{l}}{u_{c}}=\frac{z}{R},
$$

and

$$
u_{c}\left(\frac{z l}{R}\right)=R \beta E\left\{u_{c+1} \frac{z_{+1} l_{+1}}{g_{+1} R_{+1}}\right\},
$$

where the +1 subscript denotes next periods values. Note that

$$
\begin{gathered}
p=\frac{M R}{z l}, \\
w=\frac{z p}{R},
\end{gathered}
$$

and

$$
c=z l .
$$

In this equilibrium, as is commonly seen in simple CIA constraint models, only anticipated increases in the money supply have real effects (through the inflation tax), and current nominal prices and wages move proportionately with increases in the money supply. The main reason unexpected monetary shocks have no effect on real output is that eliminating cash goods also eliminates the financial friction in the liquidity model. This is because the entire money stock is now deposited in the bank, rather than just a fraction of the money stock, and there is benefit from being able to readjust one's cash portfolio between the two markets.

Given $\gamma$, finding an equilibrium of our general model with cash and credit goods can be characterized as finding a solution to $\Gamma(x, \gamma)=0$, which is a system of equations of the same order as the number of states of our model, and where $x$ denotes the endogenous variables of the model. With $\gamma=0$, it is fairly easy to see that our model with credit and (measure zero) cash goods behaves exactly like the simplified model specified here and therefore inherits its neutrality property. To establish that this would hold for $\gamma$ near zero, we would need to show that $\Gamma$ is continuous and that the Jacobian with respect to $x$ is nonzero. Continuity follows from establishing a set of conditions on the exogenous variables to ensure that prices, consumptions, and labor effort are positive and that the gross interest rate is greater than 
one. Similarly, restrictions can be found to ensure a nonzero Jacobian. However, since we are interested in whether or not we should anticipate significant changes in the real effects of monetary shocks for a change in $\gamma$ over a range that would be consistent with the decline in the ratio of money to nominal output observed over the postwar period, we choose to explore this issue quantitatively by simulating the model. 
Table 1: Real Effects of Monetary Shocks

With Low and High Inflation, and $\sigma=1^{11}$

\begin{tabular}{|c||l|l|l||l|l|l|}
\hline \multicolumn{1}{|l||}{$\theta=0.85$} & Sticky Price & \multicolumn{1}{l|}{ Model } & $(\alpha=.75)$ & Liquidity & \multicolumn{2}{l|}{ Model } \\
\hline \hline$\gamma=.8$ & $\pi=4 \%$ & $\pi=13 \%$ & $\frac{\pi=13 \%}{\pi=4 \%}$ & $\pi=4 \%$ & $\pi=13 \%$ & $\frac{\pi=13 \%}{\pi=4 \%}$ \\
\hline$\frac{P Y}{M}$ & 5.18 & 5.46 & 1.05 & 2.27 & 2.33 & 1.03 \\
\hline$\% \sigma(Y)$ & 1.232 & 1.209 & .981 & .801 & .788 & .984 \\
\hline \hline$\gamma=.4$ & $\pi=4 \%$ & $\pi=13 \%$ & $\frac{\pi=13 \%}{\pi=4 \%}$ & $\pi=4 \%$ & $\pi=13 \%$ & $\frac{\pi=13 \%}{\pi=4 \%}$ \\
\hline$\frac{P Y}{M}$ & 10.75 & 11.90 & 11.07 & 2.94 & 3.08 & 1.04 \\
\hline$\% \sigma(Y)$ & 1.231 & 1.205 & .979 & .380 & .351 & .924 \\
\hline
\end{tabular}

\begin{tabular}{|c||l|l|l||l|l|l|}
\hline \multicolumn{1}{|l||}{$\theta=0.95$} & Sticky Price & \multicolumn{1}{l||}{ Model } & \multicolumn{1}{l|}{$(\alpha=.75)$} & Liquidity & \multicolumn{1}{l|}{ Model } \\
\hline \hline$\gamma=.8$ & $\pi=4 \%$ & $\pi=13 \%$ & $\frac{\pi=13 \%}{\pi=4 \%}$ & $\pi=4 \%$ & $\pi=13 \%$ & $\frac{\pi=13 \%}{\pi=4 \%}$ \\
\hline$\frac{P Y}{M}$ & 5.46 & 6.33 & 1.16 & 2.32 & 2.49 & 1.07 \\
\hline$\% \sigma(Y)$ & 1.197 & 1.173 & .980 & .759 & .674 & .888 \\
\hline \hline$\gamma=.4$ & $\pi=4 \%$ & $\pi=13 \%$ & $\frac{\pi=13 \%}{\pi=4 \%}$ & $\pi=4 \%$ & $\pi=13 \%$ & $\frac{\pi=13 \%}{\pi=4 \%}$ \\
\hline$\frac{P Y}{M}$ & 12.5 & 17.24 & 1.38 & 3.07 & 3.35 & 1.09 \\
\hline$\% \sigma(Y)$ & 1.197 & 1.172 & .979 & .328 & .242 & .735 \\
\hline
\end{tabular}

\begin{tabular}{|c||l|ll||l|l|l|}
\hline \multicolumn{1}{|l||}{$\theta=0.99$} & Sticky Price & \multicolumn{1}{l||}{ Model } & \multicolumn{1}{l|}{$(\alpha=.75)$} & Liquidity & \multicolumn{1}{l|}{ Model } \\
\hline \hline$\gamma=.8$ & $\pi=4 \%$ & $\pi=13 \%$ & $\frac{\pi=13 \%}{\pi=4 \%}$ & $\pi=4 \%$ & $\pi=13 \%$ & $\frac{\pi=13 \%}{\pi=4 \%}$ \\
\hline$\frac{P Y}{M}$ & 9.52 & 52.63 & 5.52 & 2.84 & 3.86 & 1.36 \\
\hline$\% \sigma(Y)$ & .995 & .979 & .984 & .432 & .077 & .178 \\
\hline \hline$\gamma=.4$ & $\pi=4 \%$ & $\pi=13 \%$ & $\frac{\pi=13 \%}{\pi=4 \%}$ & $\pi=4 \%$ & $\pi=13 \%$ & $\frac{\pi=13 \%}{\pi=4 \%}$ \\
\hline$\frac{P Y}{M}$ & 37.04 & 333.33 & 9.01 & 3.66 & 4.10 & 1.12 \\
\hline$\% \sigma(Y)$ & .993 & .978 & .985 & .111 & .014 & .126 \\
\hline
\end{tabular}

\footnotetext{
${ }^{11}$ The computation in the table for the sticky price model was done with $\alpha=0.75$. To check for sensitivity to the fraction of prices that must be set in advance we also computed the $\alpha=0.25$ case. The level of output varaibility was, of course, lower, but the relative level was again invarient to the change in inflation. We also did the calculations with $\sigma=2$, and the results were essentially unchanged.
} 
Table 2: Real Effects of Monetary Shocks With Period Division

\begin{tabular}{||l||l||l|}
\hline$\sigma=1, \quad \alpha=.75$, and $\gamma=1$ & Sticky Price Model & Liquidity Model \\
\hline \hline Once to the Bank & & \\
\hline$\frac{P Y}{M}$ & 4 & 2 \\
\hline$\% \sigma(Y)$ & 1.23 & 1.03 \\
\hline \hline Twice to the Bank & & \\
\hline$\frac{P Y}{M}$ & 8 & 4 \\
\hline$\% \sigma(Y)$ & 1.23 & .49 \\
\hline \hline$\frac{P Y}{M}$ ratio twice/once & 2 & 2 \\
\hline$\% \sigma(Y)$ ratio twice/once & 1 & .48 \\
\hline
\end{tabular}

\begin{tabular}{||l||l||l|}
\hline$\sigma=2, \quad \alpha=.75$, and $\gamma=1$ & Sticky Price Model & Liquidity Model \\
\hline \hline Once to the Bank & & \\
\hline$\frac{P Y}{M}$ & 4 & 2 \\
\hline$\% \sigma(Y)$ & 1.23 & 1.04 \\
\hline \hline Twice to the Bank & & \\
\hline$\frac{P Y}{M}$ & 8 & 4 \\
\hline$\% \sigma(Y)$ & 1.23 & .49 \\
\hline \hline$\frac{P Y}{M}$ ratio (twice/once) & 2 & 2 \\
\hline$\% \sigma(Y)$ ratio (twice/once) & 1 & .47 \\
\hline
\end{tabular}


Table 3: Average Nominal Output to Money Ratios ${ }^{12}$

\begin{tabular}{|l||l|l|}
\hline$\gamma$ & Sticky Price Model & Liquidity Model \\
\hline \hline 1.0 & 4.00 & 2.00 \\
\hline .8 & 5.26 & 2.27 \\
\hline .6 & 7.14 & 2.56 \\
\hline .4 & 11.11 & 2.94 \\
\hline .2 & 25.00 & 3.45 \\
\hline 0.0 & $\infty$ & 4 \\
\hline
\end{tabular}

Table 4: Annualized Percentage Variability of Output

\begin{tabular}{|l||l|l||l|}
\hline \multicolumn{1}{|l||}{$\sigma=1$} & \multicolumn{1}{l||}{ Sticky Price } & \multicolumn{1}{l|}{ Model } & Liquidity Model \\
\hline$\gamma$ & $\alpha=.75$ & $\alpha=.25$ & \\
\hline \hline 1.0 & 1.23 & 0.30 & 1.01 \\
\hline 0.8 & 1.23 & 0.30 & 0.80 \\
\hline 0.6 & 1.23 & 0.30 & 0.59 \\
\hline 0.4 & 1.23 & 0.30 & 0.38 \\
\hline 0.2 & 1.23 & 0.30 & 0.19 \\
\hline 0.0 & 1.23 & 0.30 & 0.00 \\
\hline
\end{tabular}

\begin{tabular}{|c|c|c|c|}
\hline$\sigma=2$ & Sticky Price & Model & Liquidity Model \\
\hline$\gamma$ & $\alpha=.75$ & $\alpha=.25$ & \\
\hline 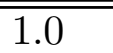 & 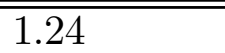 & 0.31 & 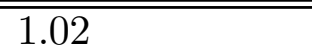 \\
\hline 0.8 & 1.21 & 0.30 & 0.80 \\
\hline 0.6 & 1.20 & 0.30 & 0.58 \\
\hline 0.4 & 1.19 & 0.30 & 0.38 \\
\hline 0.2 & 1.18 & 0.30 & 0.18 \\
\hline 0.0 & 1.18 & 0.30 & 0.00 \\
\hline
\end{tabular}

\footnotetext{
${ }^{12}$ These ratios were uneffected by a change in the stochastic process driving the shocks, whether or not there were real, monetary, or both kinds of shocks, or the value of $\sigma$. The results for the sticky price model were also independent of $\alpha$.
} 


\section{Figure 1}

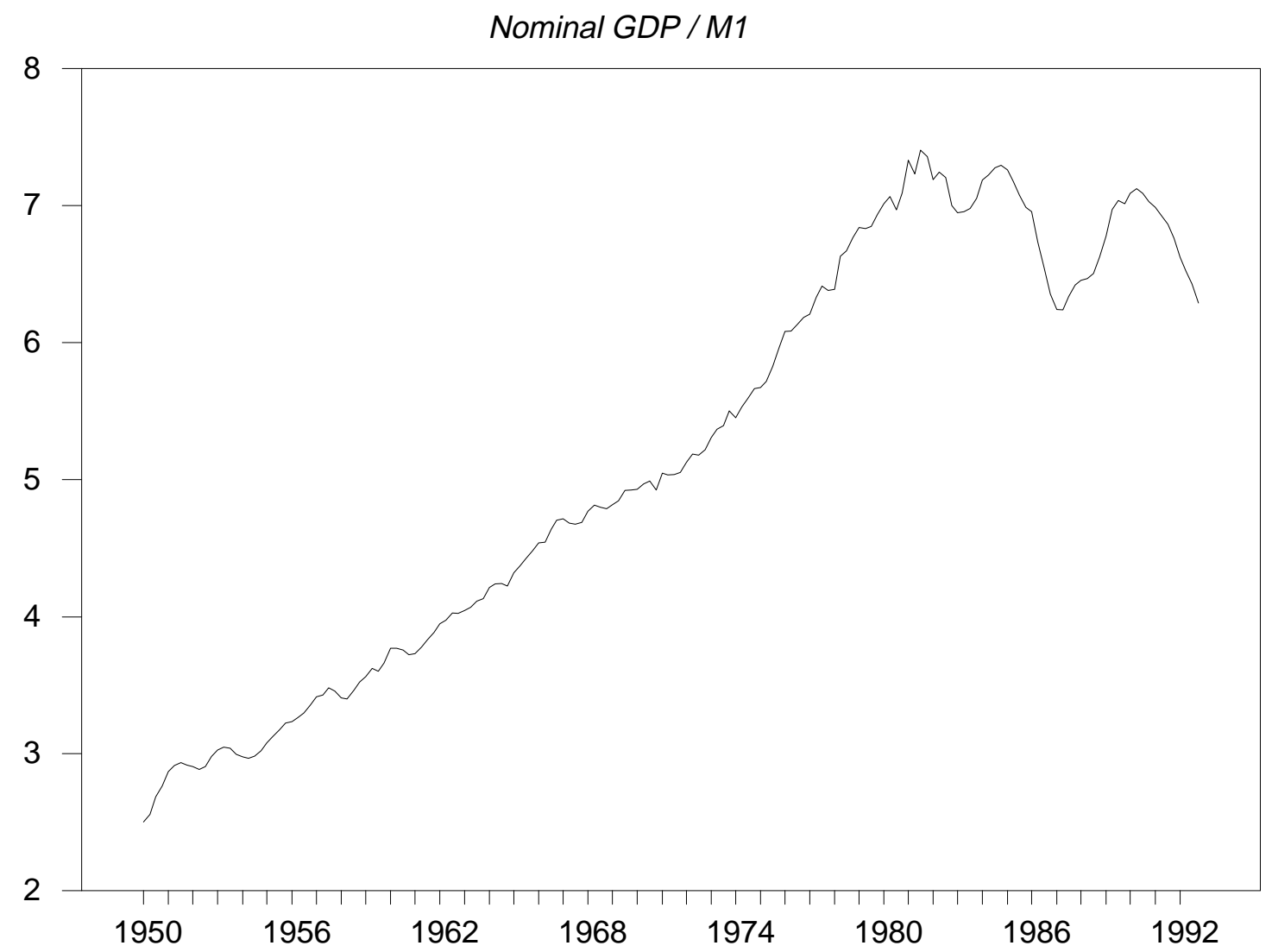

Figure A.1: 


\section{Figure 2}

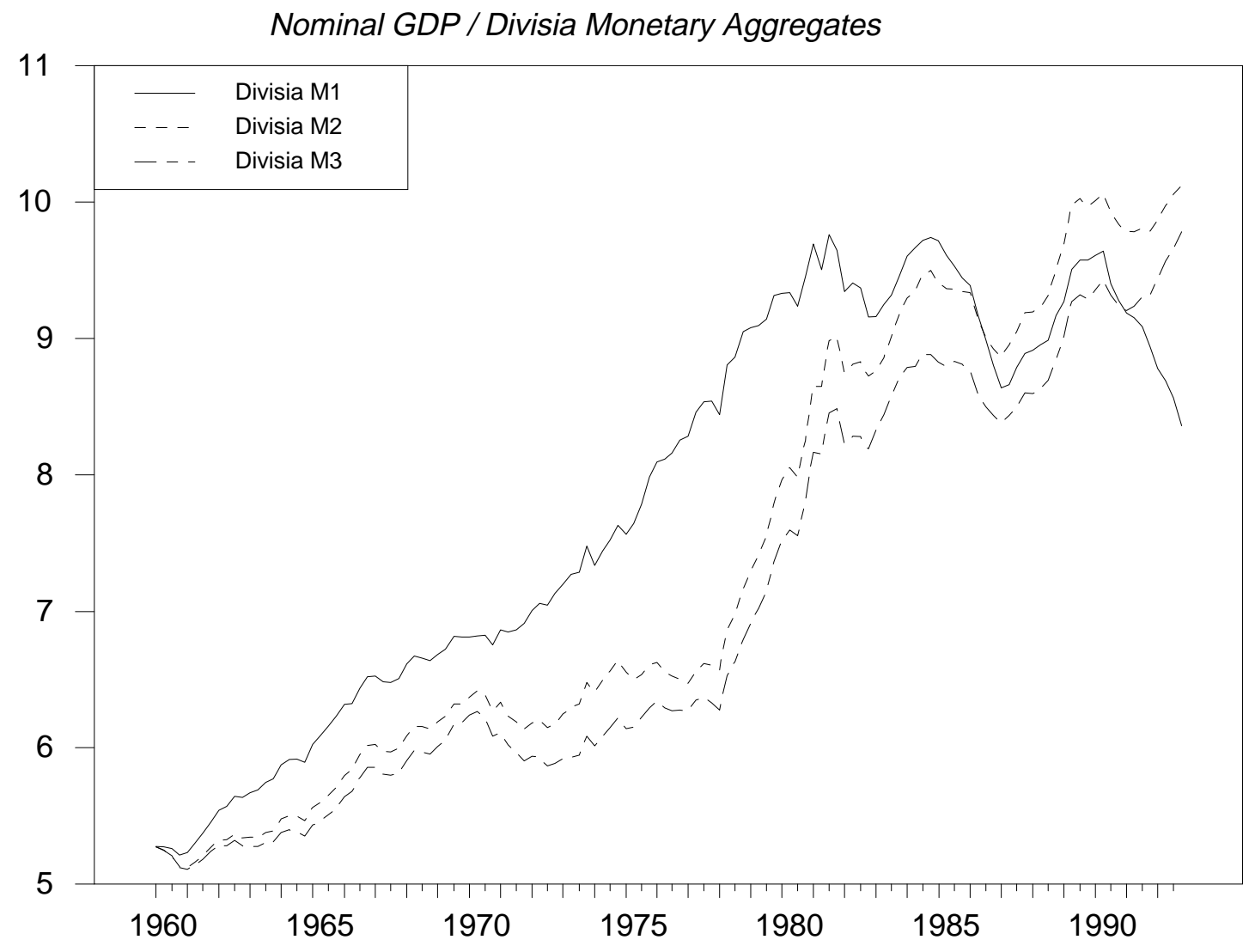

Figure A.2: 